\title{
رؤية العالم بين الواقع والأدب
}

\begin{abstract}
هنى المتولى من
تسعى هذه المقالة للتعريف بالبنيوية التوليدية كمنهج قابل للنطبيق فى فهم طبيعة الرواية العربية.

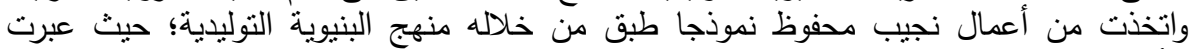

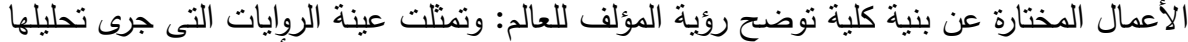

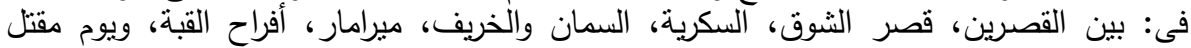
الزعبم. - 1ان.
\end{abstract}

\section{مقدمة}

سادت فترة غير قصيرة من الزمن فكرة أن الأدب انعكاس للواقع حتى جاء لوسيان

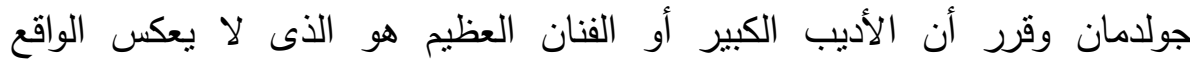

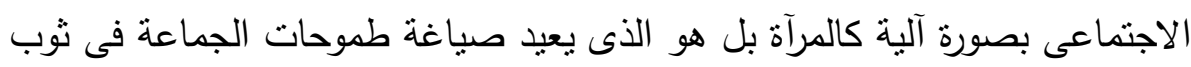

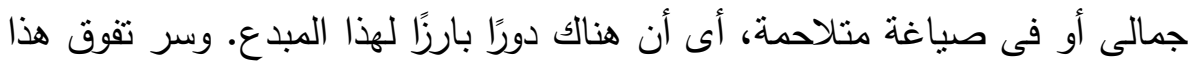

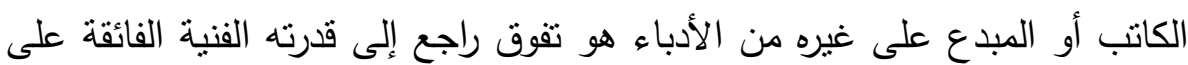

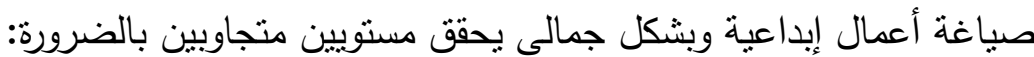

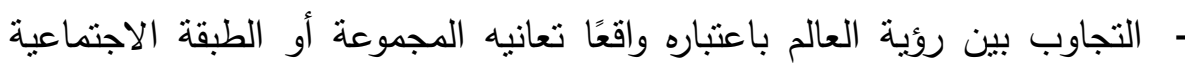

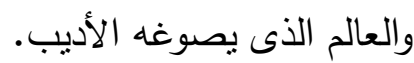
- التجاوب بين هذا العالم المصاغ والوسائل الأدبية المستخدمة فى صياغته من

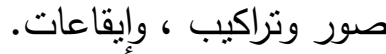
* مدرس مساعد، المركز القومى للبحوث الاجتماعية والجنائية.

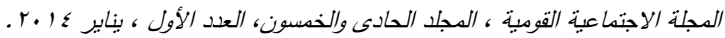




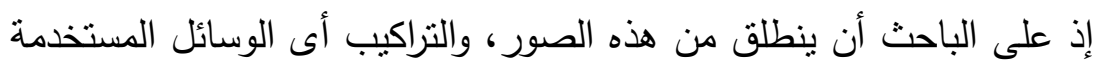

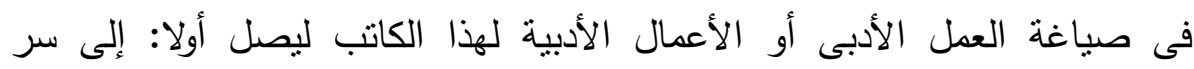

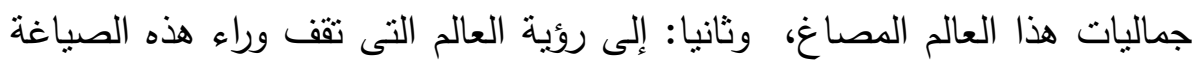
ومن ثم واقع المجموعة الاجتماعية أو الطبقة الاجتماعية.

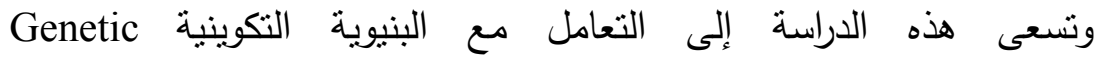

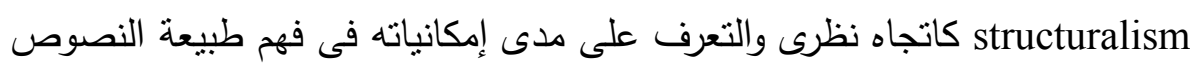

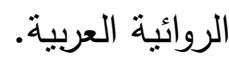
ولهذا فجدير بنا أن نأخذ نجيب محفوظ نموذجًا نطبق عليه منهج البنيوية

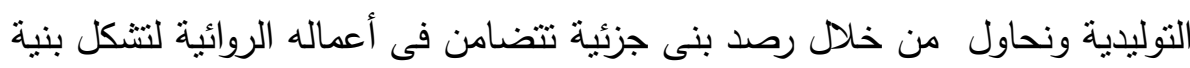

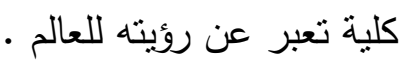

\section{أهداف الدراسة وتساؤلاتها}

تهاف الدراسة إلى التعامل مع البنيوية التكوينية كاتجاه نظرى والتعرف على مدى

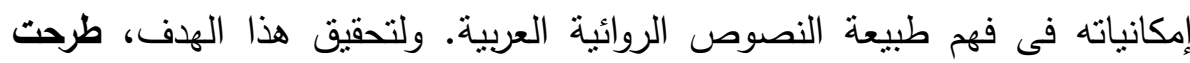
الباحثة مجموعة من التساؤلات أهمها: 1- ما رؤية الروايات محل الدراسة للذات في علاقتها بالآخر ؟

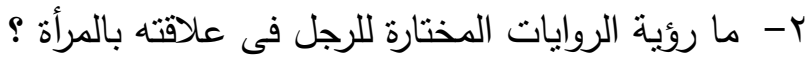
r- ما رؤية الأديب للعالم التى يمكن التوصل إليها من خلال تحليل رواياته؟ بالئ

\section{الإطار النظرى للدراسة} البنيوية التكوينية أو التوليدية (لوسيان جولدهان)

تعد البنيوية التكوينية أو النوليدية فرع من فروع البنيوية، نثأ استجابة لسعى بعض البوليدان

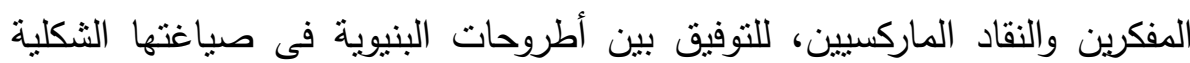

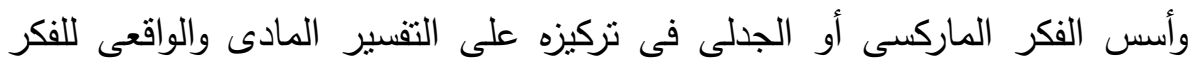
والثقافة عموماً. 


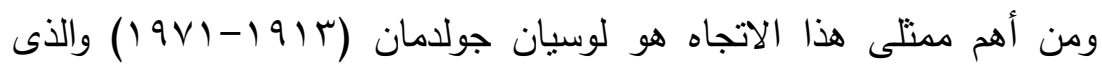

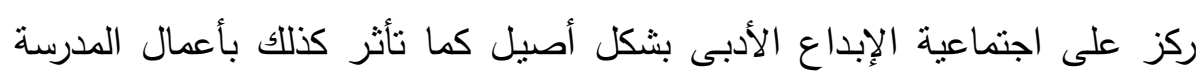

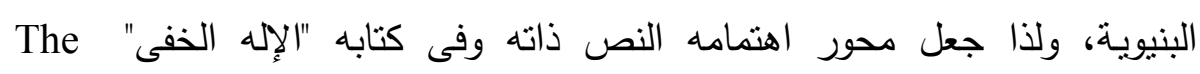
Hidden God

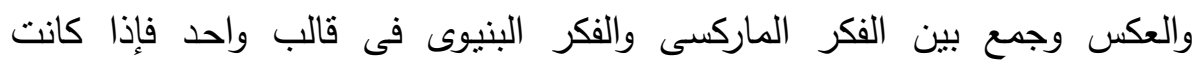

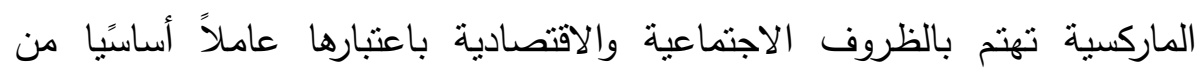

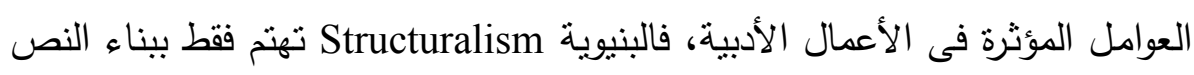

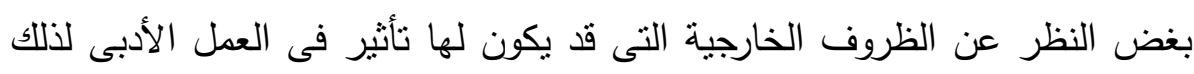

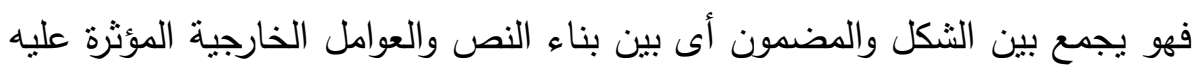

ويصوغ جولدمان نظريته على أساس مفهومين: مفهوم البنيوية وهو بعنى

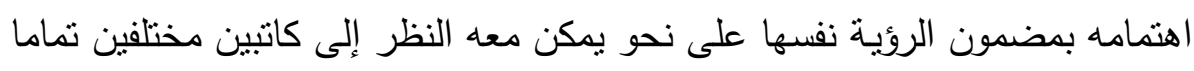

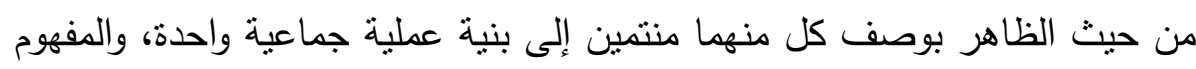

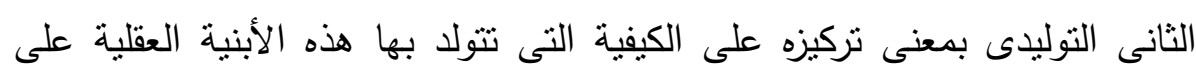

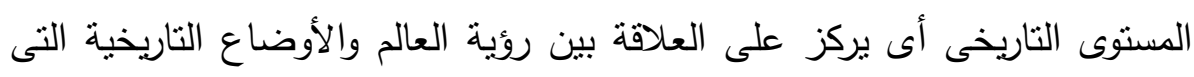

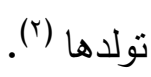

ومن هذا المنظور، فإن البنية النى يأخذ بها جولامان، ترتبط بالأعمال

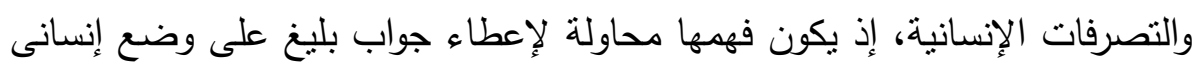

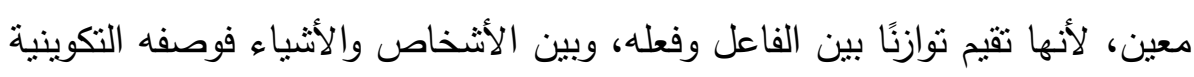

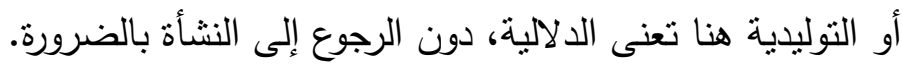




\section{المفاهيم التى تتضمنها البنيوية التكوينية}

هناك مفاهيم جوهرية يجب أن نوضحها فى منهج "جولدمان" أهم هذه الكفاهيم :

رؤية العالم World vision

لقد صاغ جولامان منذ عام VI9 19 مسلمة أسست منهجه فى دراسة العلاقة بين

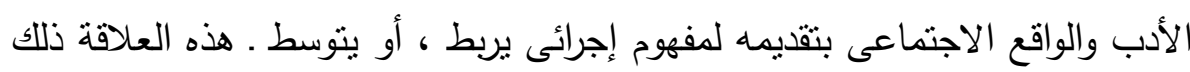

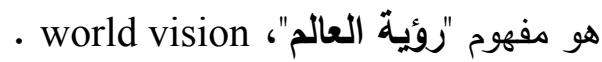

ويرى جولدمان أن "رؤية العالم هى وجهة نظر الكاتب التى يشترط أن تكون

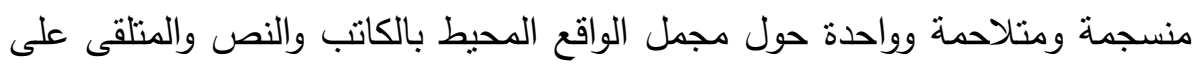

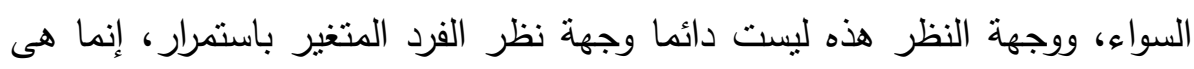
منظومة لفكر مجموعة من البشر الذين يعيشون فى ظروف اقتصادية واجتماعية متماثلة والكاتب يعبر عن هذه المنظومات بشكل بنطوى على دلالة كبيرة" (r). ويمكن مناقثتة مفهومين أساسيين برتبطان بمفهوم روئية العالم لاى جولدمان،

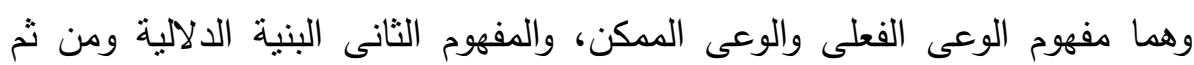
سنقوم بتوضيح هذين الدفهومين وشرحهما:

\section{الوعى الفعلى والوعى الممكن}

"ققصد جولادمان بالوعى الفعلىReal consciousness الوعى الموجود تجريبيًا على المعى"

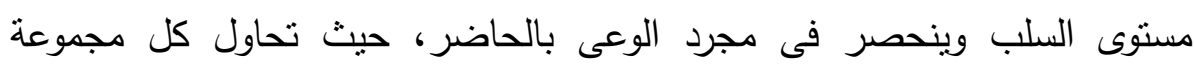

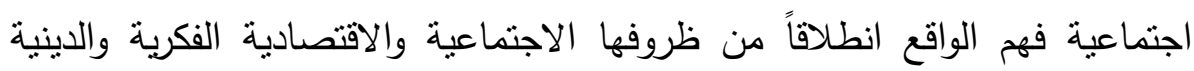

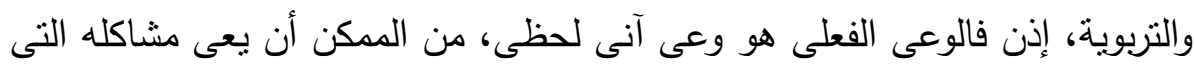

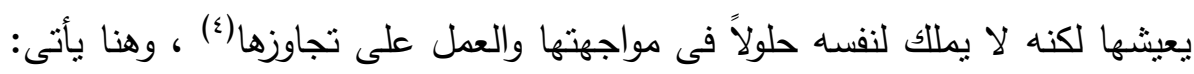
"الوعى المكن" Possible consciousness الذى ينشأ عن "الوعى الفعلى"، ولكنه

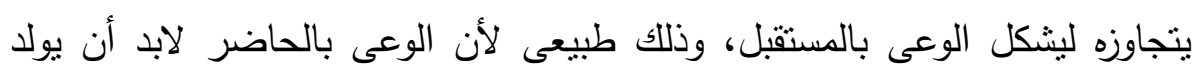

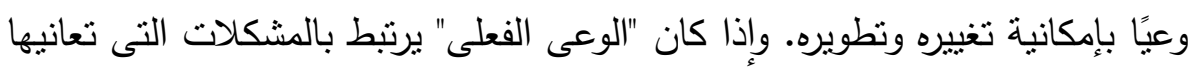


الطبقة، أوالمجمعة الاجتماعية من حيث علاقاتها المتعارضة ببقية الطبقات،

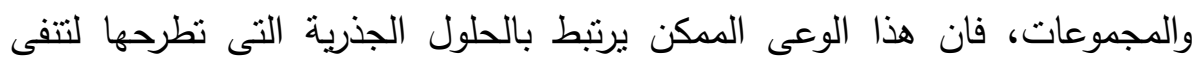

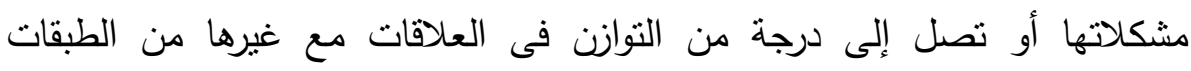
والمجموعات (م).

significant structure البنية الدلالية (الدالة)

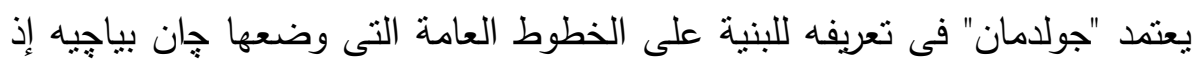

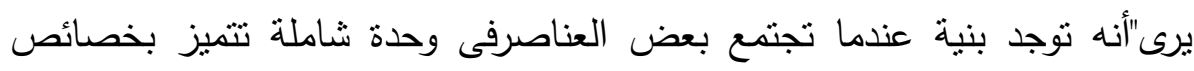

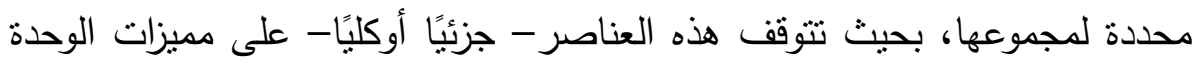

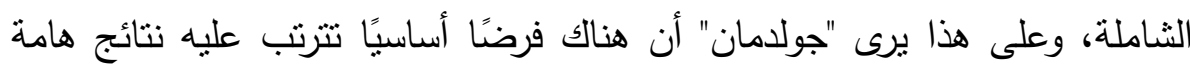

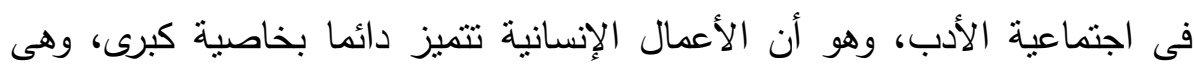

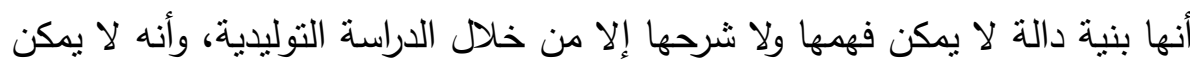
الفصل بين عمليتى الفهم والتفسير فى أى بحث إيجابى لهذه الأعمال"(7).

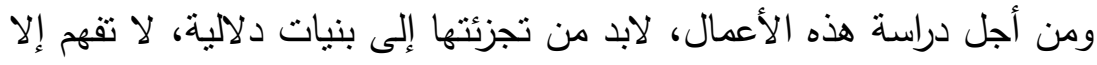

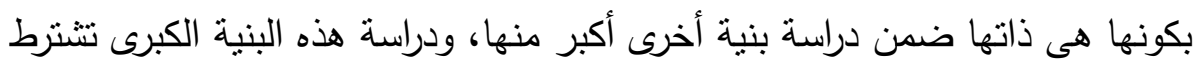

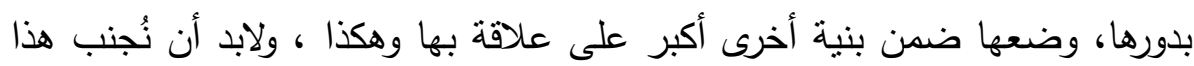

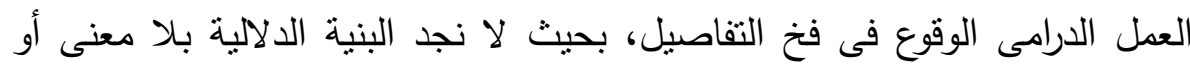

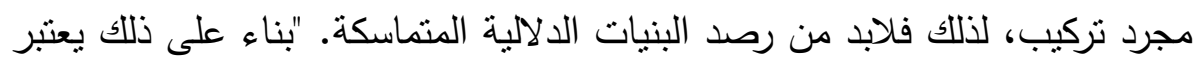

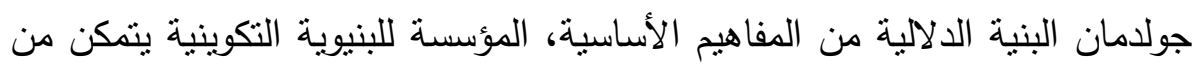

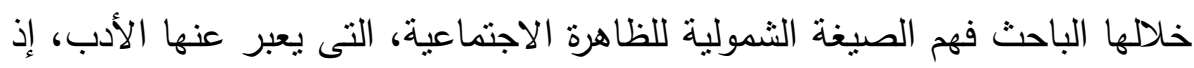
الدقصود بهذا الدفهوم هو الدعنى الدلالى للبنية الدالة على وعى الجماعة. هذه البنية

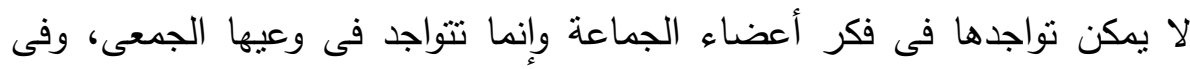

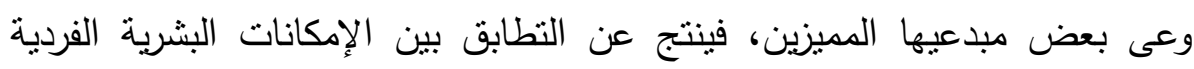
والوضع التاريخى ما يسمى بالعبقرية" (V). 


\section{أساليب الدراسة}

سوف نعرض فيما يلى للأساليب المختلفة المستخدمة فى تحليل وفهم الروايات

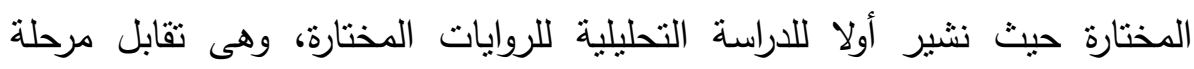

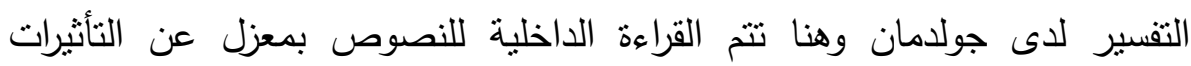

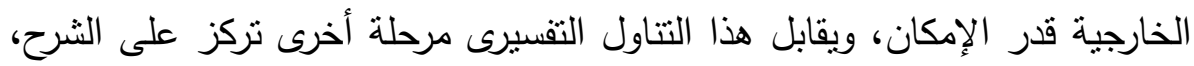
وهى تتتاول القراءة السابقة بشكل موسع يعتمد على المقابلة والمراوحة المستمرة بين الداخل والخارج، وهذا يرتبط إلى حد كبير بالفهم والتحليل. وكلا المرحلتين السابقتين

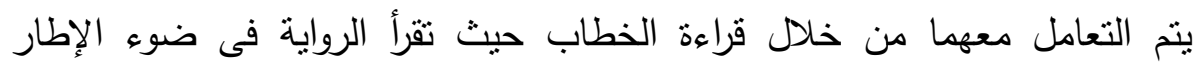

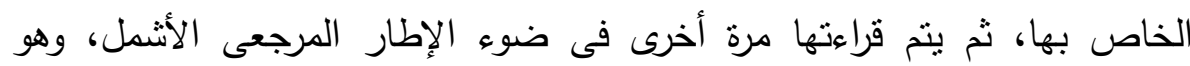

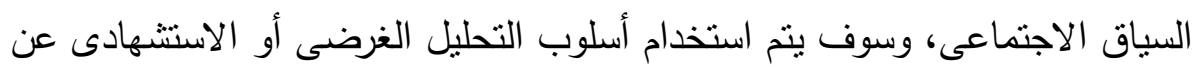
طريق اختيار فقرات من الروايات الرختارة.

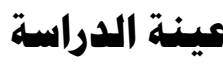

تم اختيار عينة عمدية من روايات نجيب محفوظ عبرت عن ثلاثة مراحل: المرحلة الأولى ما بين الحربين(المرحلة الليبرالية المصرية قبل الثورة) واختارت الباحثة منها: ثلاثية نجيب محفوظ (بين القصرين ـ قصر الثنوق ـ السكرية)

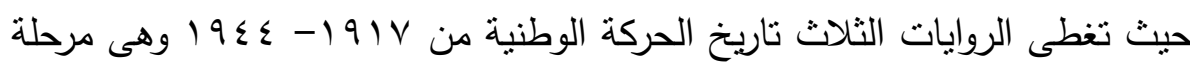
تتسم بالنضال ضد الاستعمار ، واحتدام الصراع الطبقى. المرحلة الثانية وهى مرحلة الاثتراكية (المرحلة الناصرية)

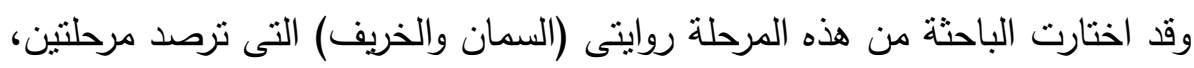

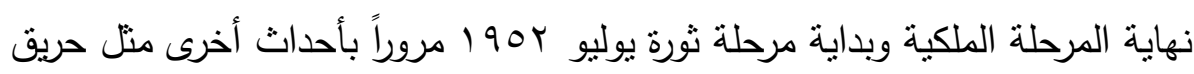

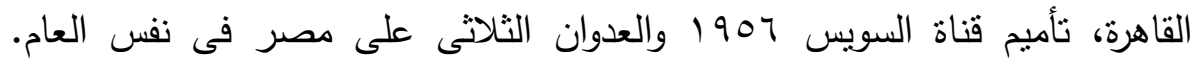
الرواية الثانية وهى (ميرامار) ، وهى ترصد التغيرات الاجتماعية بعد صدور قوانين 
التأميم فى يوليو (197 التى عرفت باسم القوانين الاشتراكية وتأثير هذه القوانين من

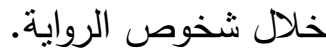

أما المرحلة الثاثثة وهى مرحلة اللييرالية الجديدة بعد الثورة وقد اختارت الباحثة منها روايتى (أفراح القبة، ويوم قتل الزعيم)، الرواية الأولى "أفراح التهاح

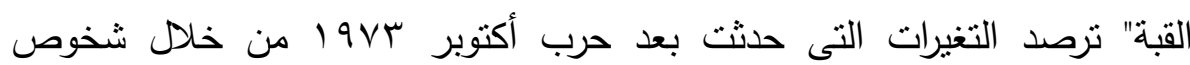
الرواية. الرواية الثانية "يوم قتل الزعيم" ترصد بشكل صريح التغيرات التيرات النى حدثت

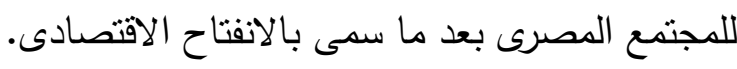

أولا: هرحلة ها بين الحربين ، (المرحلة اليبرالية الصرية قبل الثورة) وفيها ركز محفوظ على كتابة الروايات الاجتماعية الواقعية المعاصرة، واهتم فيها

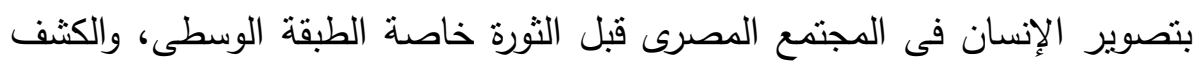

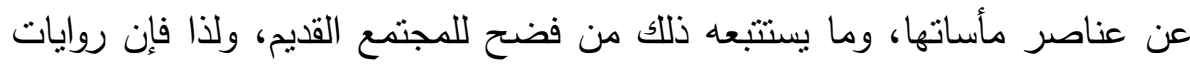

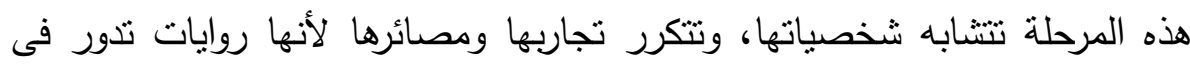

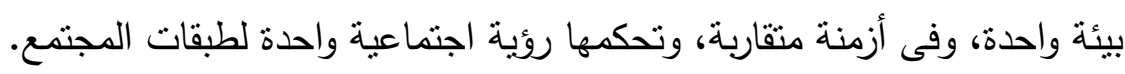
1- - موئة الذات فى علاقاتها بالآخر

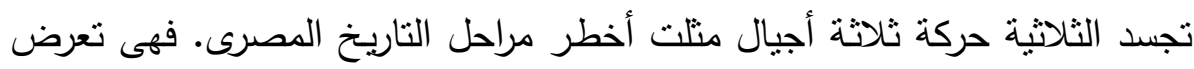

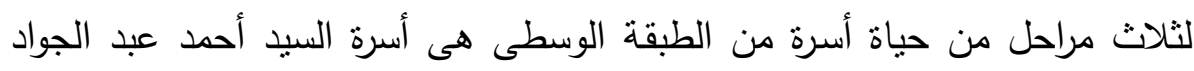

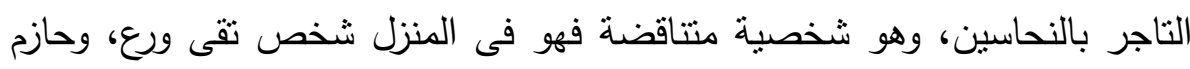

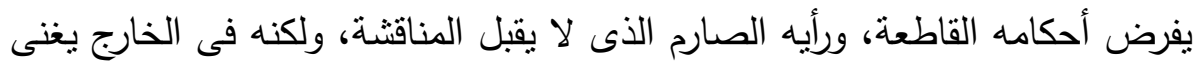
ويضرب الدف فى سهراته ويشرب الخمر ويتصل بالنساء.

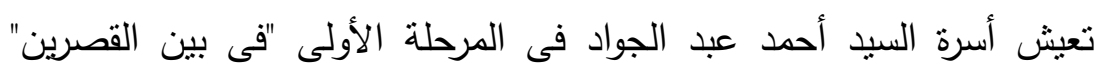

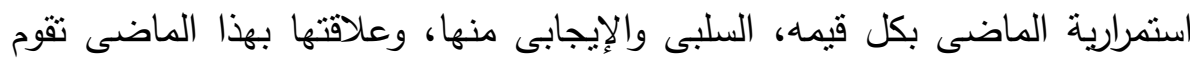

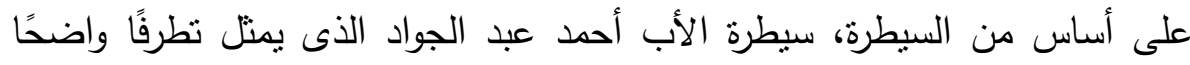

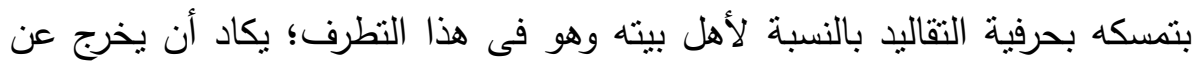


حدود الواقعية مع قيام المبررات الكافية لهذا النطرف حياتيًا فيخرج عن الإطار الفردى ليجسد قيمًا سابقة.

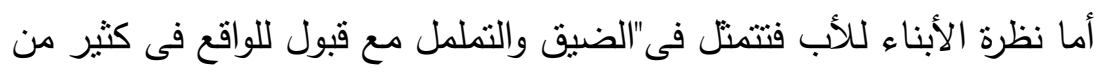

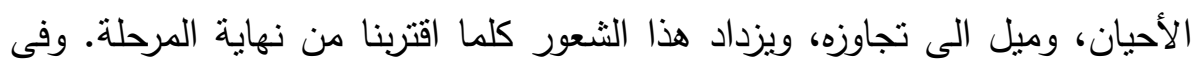

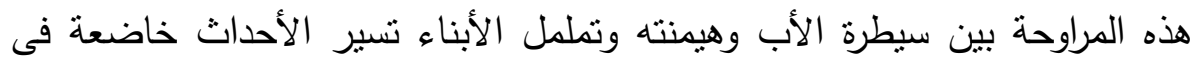

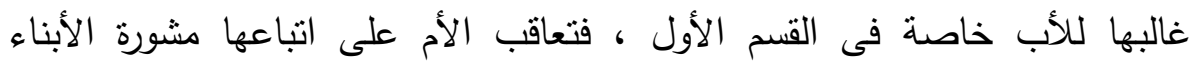

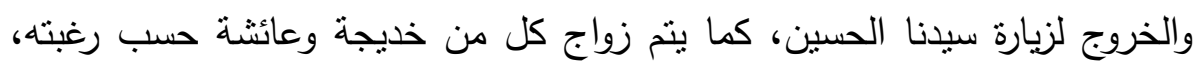

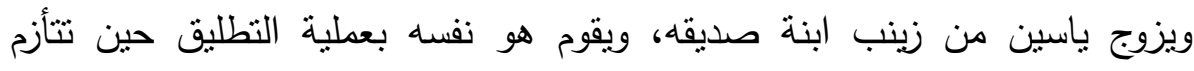

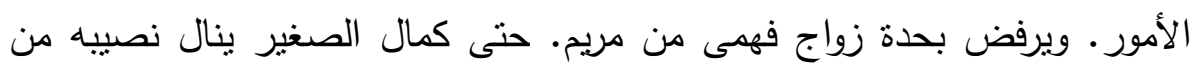

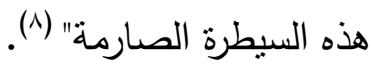
"وتقام لنا الرواية الحدث التاريخى السياسى والمتمتل فى تتصيب السلطان

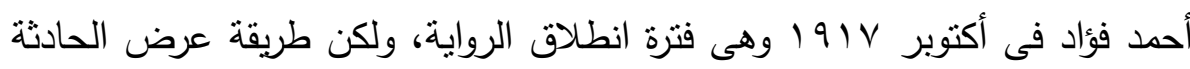

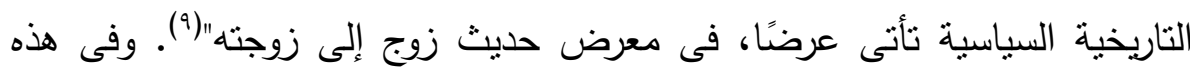

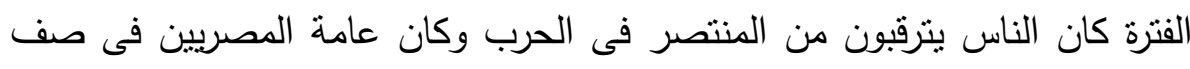

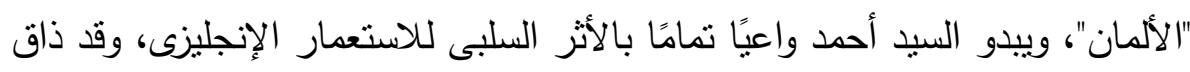

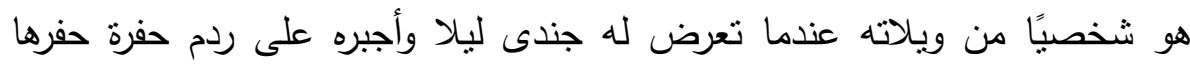

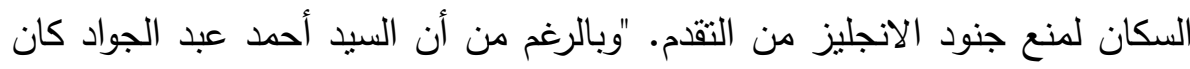

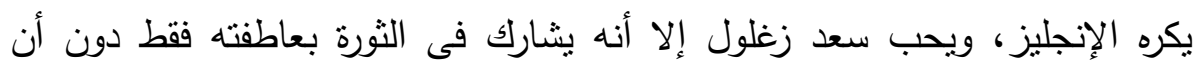
تترجم هذه إلى عمل واضح المعالم، فهو يقف عند حدود التوقيع على التوكيل

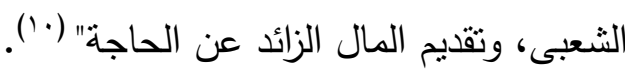

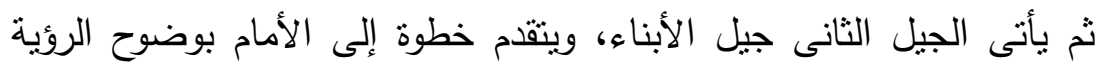

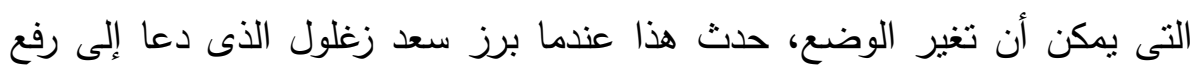

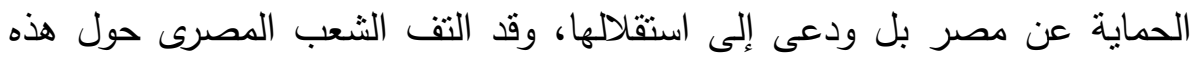


الفكرة، فتعانقت بذلك الموهبة الفردية ممنلة فى سعد زغلول مع الظرف التاريخى

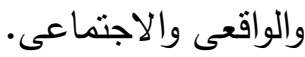

لقد آزر الشعب المصرى سعد زغلول، وفى بيت أحمد عبد الجواد كان فهمى

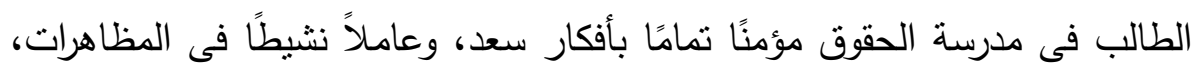
وفى توزيع المنشورات فقهمى بذلك لم يكتف بالوعى الفعلى المنتشر فى أسرته، بل شق حجب المستقبل للمطالبة بشىء آخر، يتعلق باستقلال مصر، ومد يده مباشرة

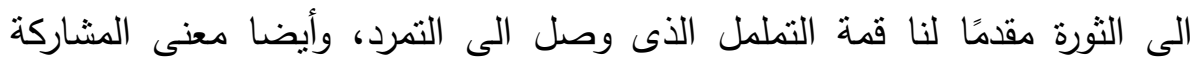

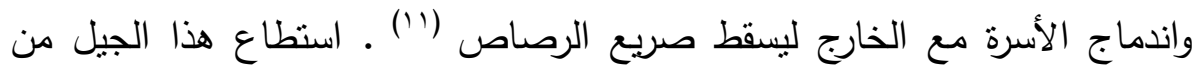

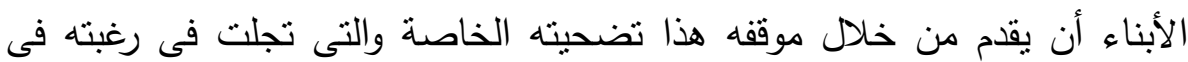

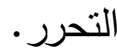

المرحلة الثانية فى "قصر الثوق" تقدم لنا الجيل الأوسط المتوتز القلق، الذى رلى اختلطت الأضداد فى داخله فاضطرب فكره ونفسيته وهذا ما يميزه عن سابقه ولاحقه، فلا هو مستقر كسابقه ولا ثابت الخطى كلاحقه، ولكن قُّر لله أن يعيش فى الوسط

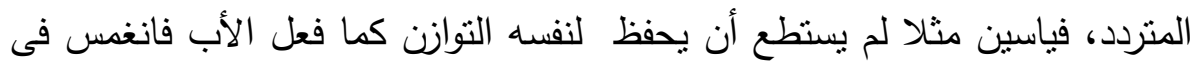

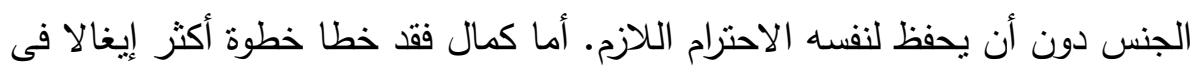
الفكر، فدفع ثمنا يفوق ما دفحه فهمى الثهيد، فلا استطاع أن يحقق الثهادة، ولا استطاع أن يمارس حياته أو يقدم لنا فاعلية فكره، فظل أعزب فكرًا وجسدًا (r'). ويبقى فى إطار الوسط المتردد أيضا الجيل السابق، فأحمد عبد الجواد يمارس سلطته ولكن دون فاعلية بارزة فهو ينتبث بما يراه حقًا له ويستمر فى فرض إرادته

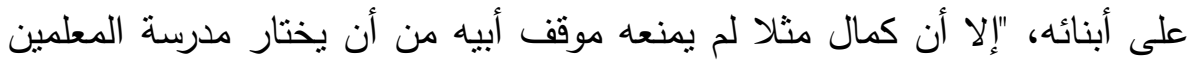

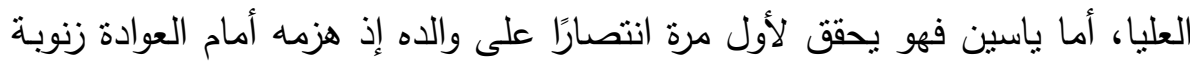
فتزوجها ليغرق أحمد عبد الجواد بعدها فى أمراضه وآلامه" (r'ا'). "وفى الجزء الثالث تبدأ طلائع الجيل الثالث الذى نلتقى به صغيرًا فى أول هذا الجزء فهناك اليمينية الدينية المنطرفة التى يمنلها عبد المنعم الأخ المسلم، واليسارية 


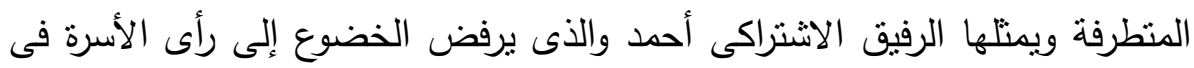

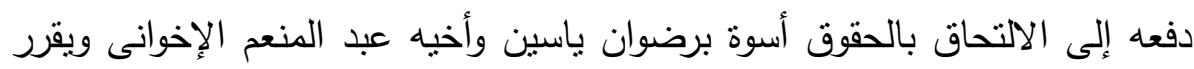

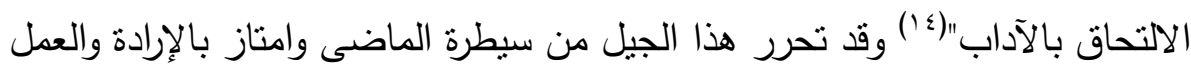

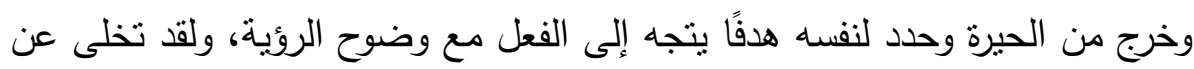

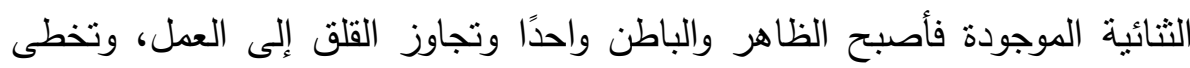
الوعى الفعلى المنتشر فى الجيل السابق الى الوعى الممكن الذى ينعلق باستقلال

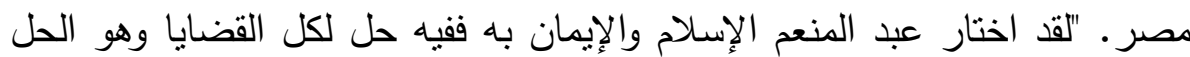
الناجح لكل المشاكل، وحين ترسخ هذا فى ذهنه يتجه إلى تحقيقه واقعيًا فعلى مستوى الإنى

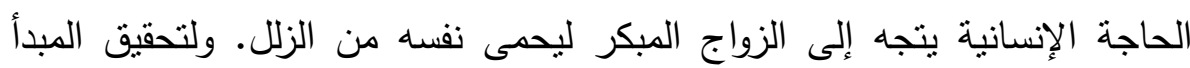

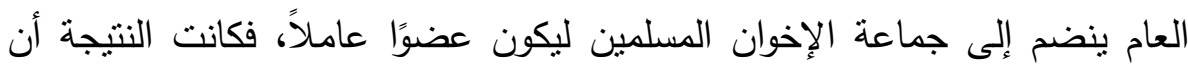
قبع فى السجن فى انتظار الغد" (10) "ولا يخرج أحمد عن هذا المسلك وإن اختلف النهج، فقد اتجه نحو الإيمان بالإنسانية والغد، واختار الماركسية بفكره وممارساته واختلط بالحياة ساعيًا نحو تحقيق

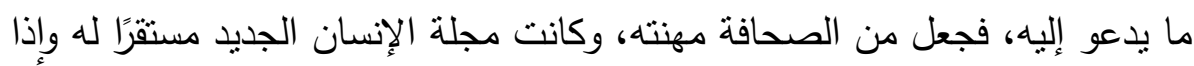
كان كمال مشغولاً بنيارات الفكر التجريدية بناقتشها على القهوة فإن أحمد يلتقى بأقرانه

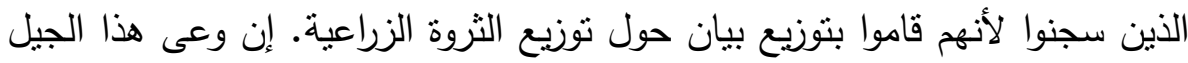

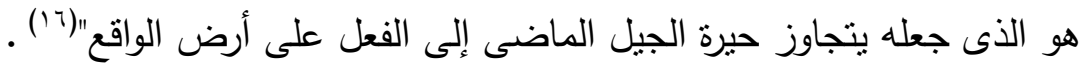

\section{r - ب - بوية الرجل لعلاقته بالمرأة} علاقة السيد أحمد بالمرأة متمثلة بنلك العلاقة الزوجية "التى قامت على القهر من

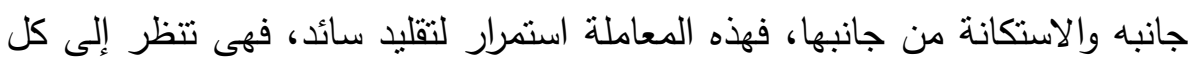

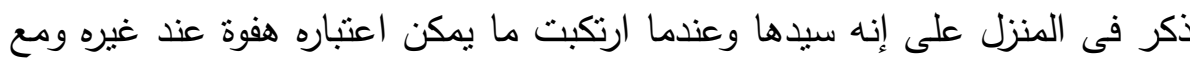

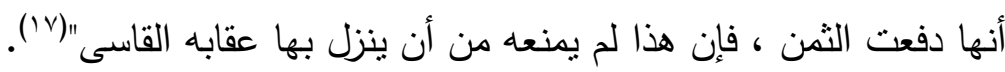


وأمينة تمتل الوعى الفعلى البدائى فهى امرأة نمطية سلدت مقاليد أمورها للزوج

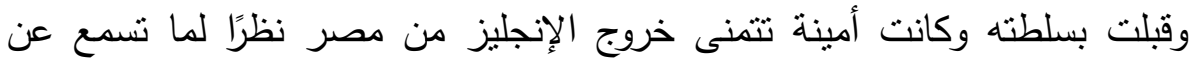

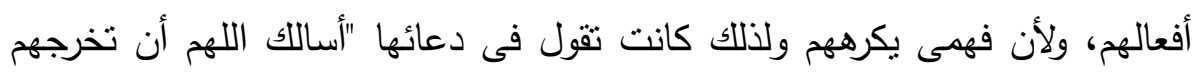
من ديارنا إكراما لفهمى الذى لا لا يحبهم".

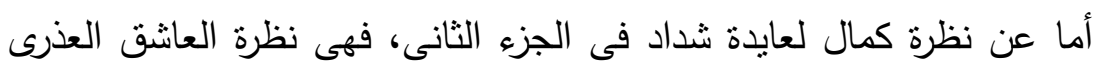

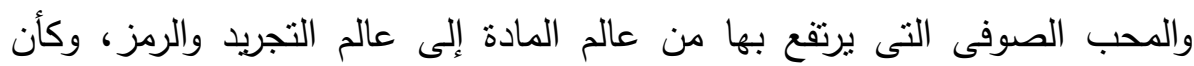
الإيمان بها يعنى الإيمان بالمثل والمبادئ كافة.

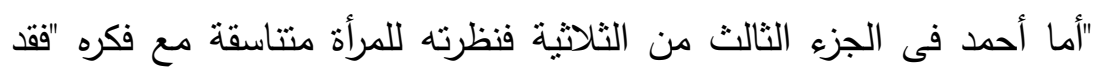
كرر نفس معاناة كمال العاطفية حينما أحب علوية صبرى الفتاة الارستقراطية تمامًا

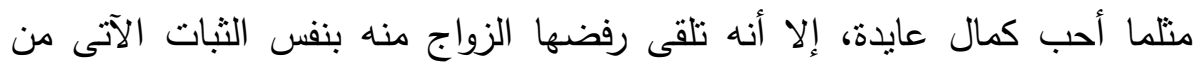

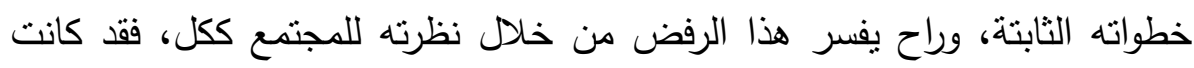

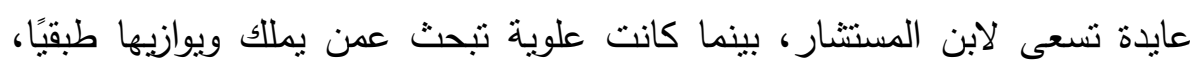

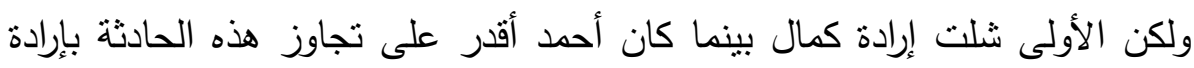

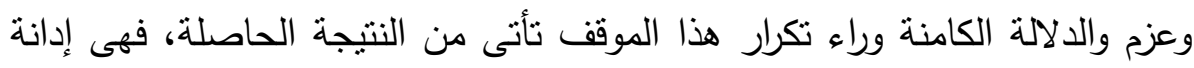

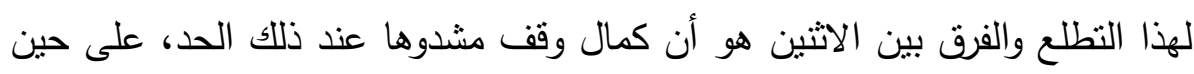

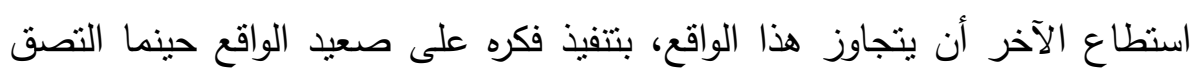

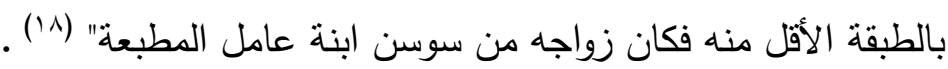

\section{ثانيا : هرحلة الاشتراكية (المرحلة الناصرية)}

ثم يتجاوز نجيب محفوظ تصوير المشكلات الاجتماعية وينتل إلى تصوير المشكلات النفسية والفكرية بعد الثورة، ويطلق على هذه المرحلة فى أدب نجيب محفوظ المرحلة الوجودية، وفيها ينتقل محفوظ من تصوير العالم الخارجى بتفاصيله

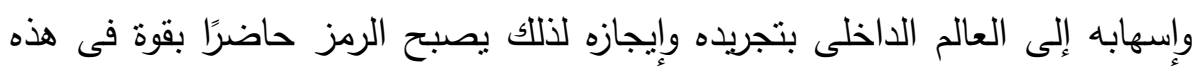


الأعمال كما تتسم هذه المرحلة كما يذكر خالد عانشور"بسيطرة الفكرة كبطل رئيسى للعمل تتجسد فى شخص واحد تتجمع فى يده خطوط العمل، ولا تفهم بقية

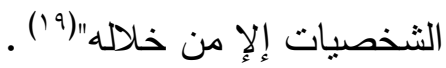

1- روئة الذات فى علاقتها بالآخر (المجتمع)

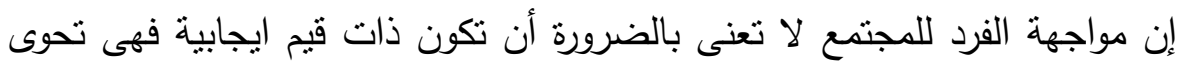
الكثير من السلبيات، وهذا ما نراه فى مواجهة عيسى الدباغ لمجتمعه. يمتد شريط

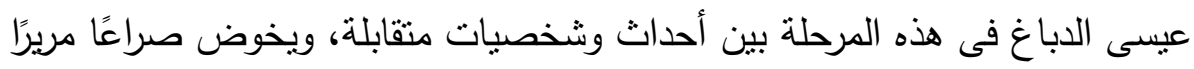

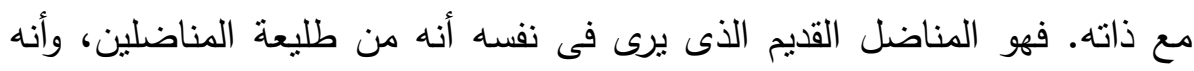
أعطى الكثير حتى استطاع أن يصل إلى مركز مدير مكتب الوزير ثم نحدث ألى أحداث مفاجئة عديدة نوقف قطار حياته المتوجه إلى مقعد الوزارة هذا السقوط السريع وما

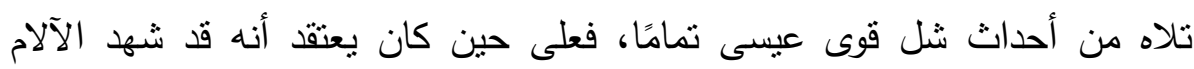

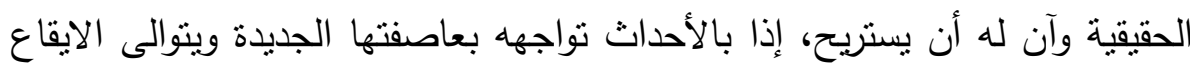

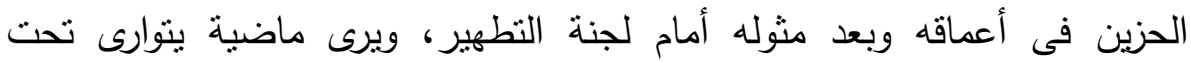

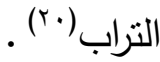

ويواجه عبسى مجتمعه، وما يحدث فيه من تغيرات بالانكفاء على الذات.

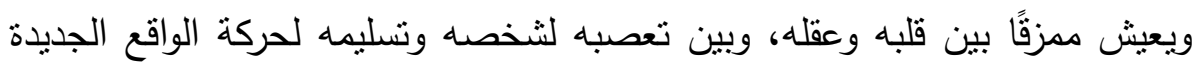
وهو يمثل بذلك الوعى الفعلى السلبى، أما أصدقاؤه فيققون على النقيض، فهم

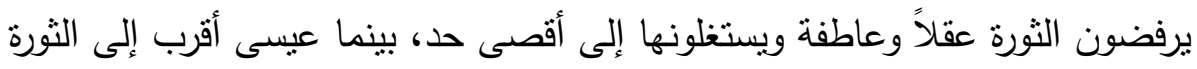
منهم فى اللحظات الحاسمة ونلمس هذا فى الموقف الذى اتخذه حينما راح هؤلاء

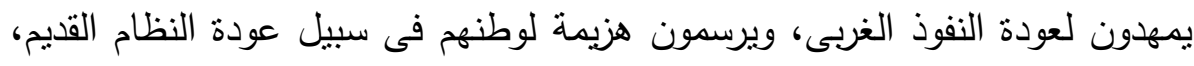

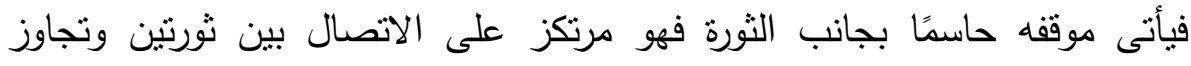

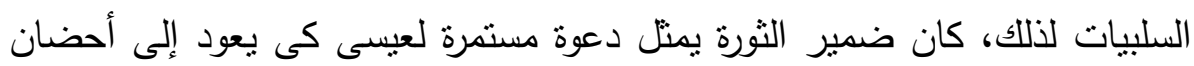


المجتمع الجديد وبذلك يكون قد تجاوز الوعى الفعلى السلبى إلى الوعى الممكن الذى يغير الواقع" (rا') .

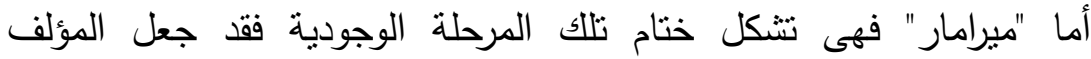
الأحداث تروى من خلال وجهات نظر أربع فجمع بين الروئية الفردية وفكرة المجموع المانع

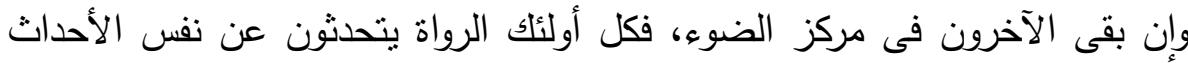

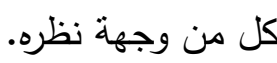

"يواجه عامر وجدى الصحفى القديم والمناضل الثورى القديم المجتمع الجديد"

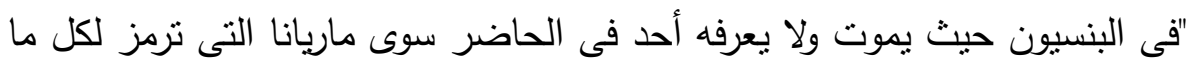
يمقته وهو المناضل الثورى القديم الذى عاش من عصر الحزب الوطنى إلى الاتحاد التهاد

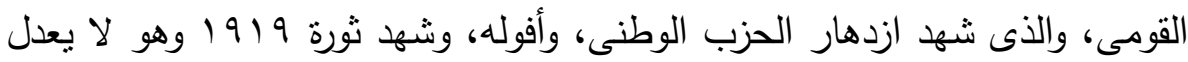

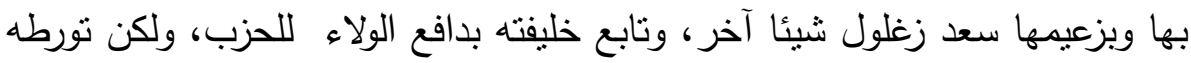

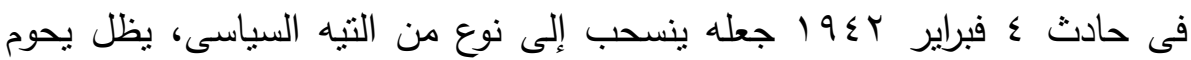

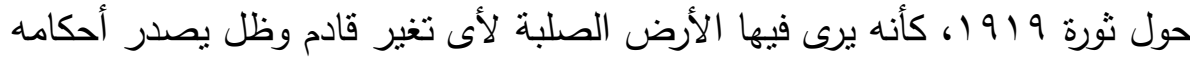

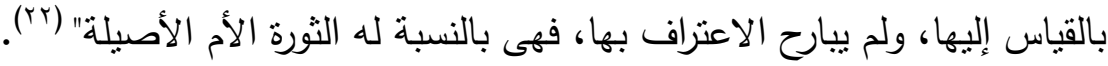

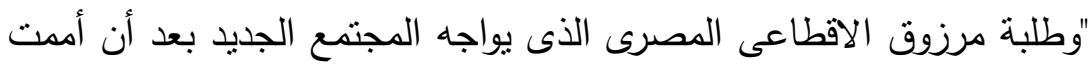

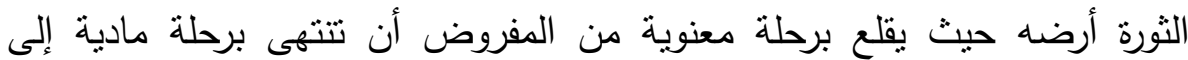

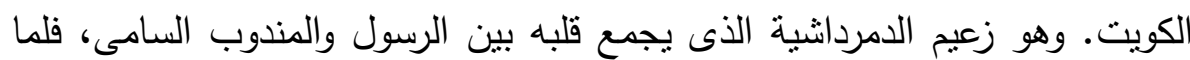
تغير الحال لم يطق سماع أية نظرية تبرر مأساته التاريخية"(rT).

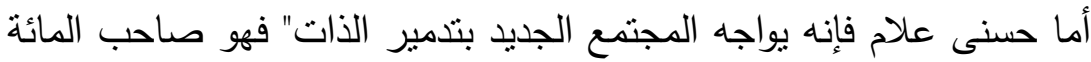
فدان، يأتى للإسكندرية ليبدأ مشروعًا تجاريًا، والثورة هنا لا تمس أملاكه ولكن تصييه بتغير القيم الاجتماعية، مما يجعل قريبة له ترفض الارتباط به بالزواج لأنه لا يحمل شهادة علمية. ونتيجة لهذا الرفض يندفع حسنى علام فى رحلة للانسلاخ عن ماضية

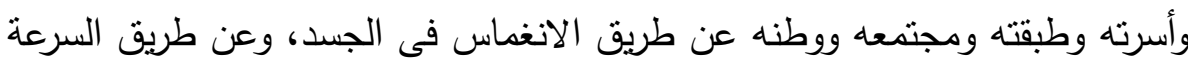


الجنونية بالسيارة تلك السرعة المشيرة إلى الهلالك المادى المنتظر، والموحية بالهلاك

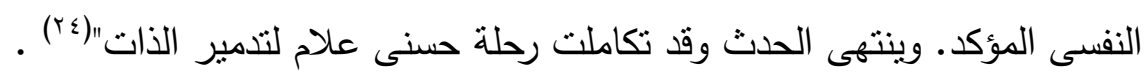
ويكتسب سرحان البحيرى فى بنسيون ميرامار بنية دالة من حيث نوقيت هذا التوقف "فهو ينحبس فى البنسيون، أو فى بؤرة الماضى في نفي نفس اللحظة التى يحسم

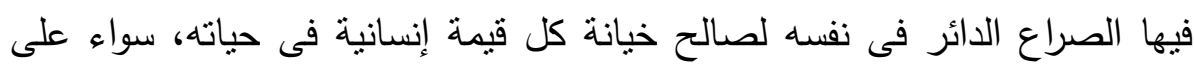

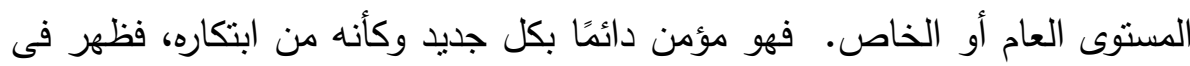

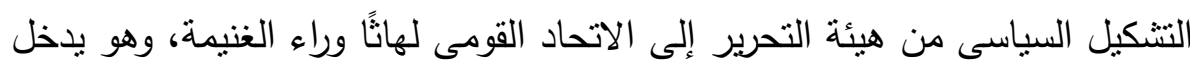

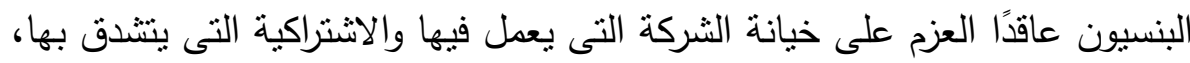

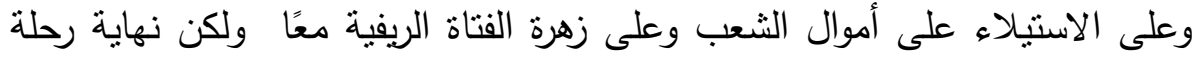

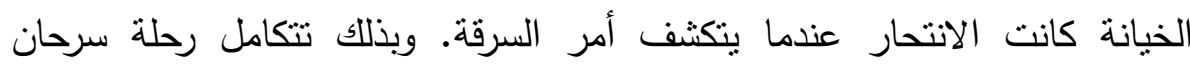
البحيرى فى بؤرة الماضى متجاوزة مرحلة التممير المعنوية إلى مرحلة التدمير التيار

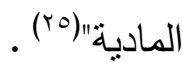

ويواجه منصور باهى مجتمعه برحلة خيانة أخرى" وهى التمزق ما بين الرغبة

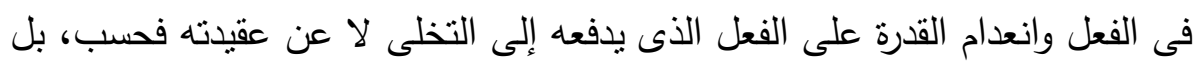

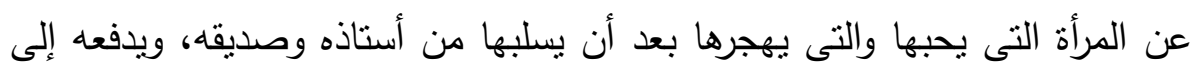

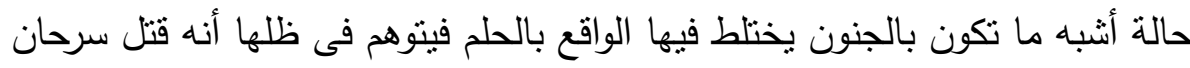

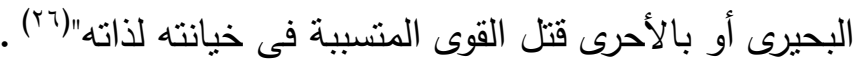

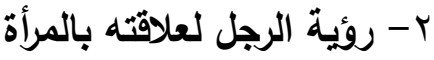

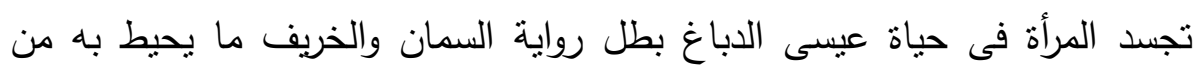

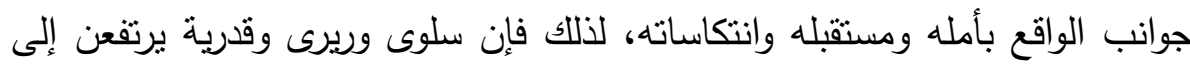

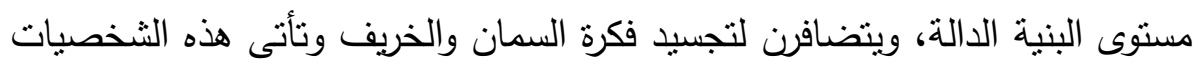

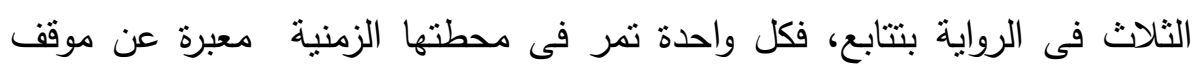


معين ومواكبة التغيير الحادث فى شخصية عيسى ويشكلن فيما بينهن تكاملاً واضحًا على مستوى الدلالة.

"تأتى سلوى أولا بجمالها وانتماء أسرتها السياسى إلى الأسرة الحاكمة ويحاول"

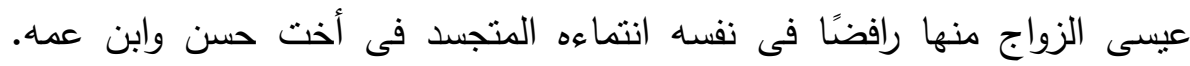

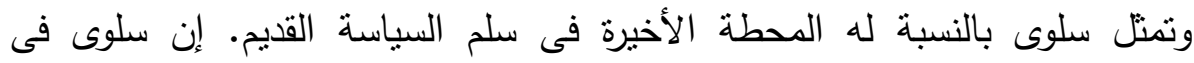

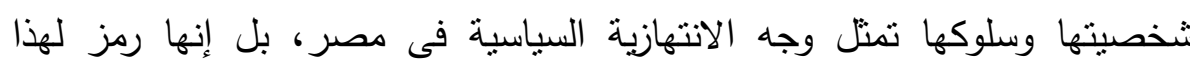

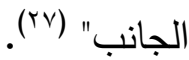

وتعود المرأة مرة أخرى حين يبدأ معاناته، "تأتى كل من ريرى وقدرية لتقدما وجهين من وجوه عيسى، ولتكثفا موقعين من مواقعه، فهما تماما كقلبه المتخلف المشدود إلى الماضى وعقله الذى يحاول أن يثد إليه الاقتتاع بالثورة ـ وتجسدان

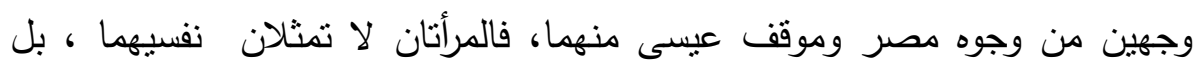

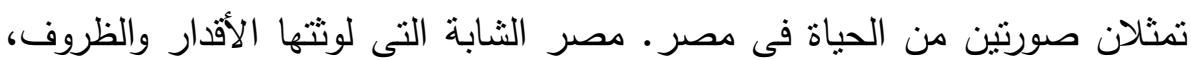

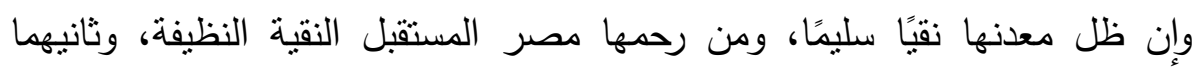
مصر الكهلة العجوز التى لن تلا إلا البوار والتى تتجه نحو الثيخوخة بخطى سريعة"

"يلتقى أولا: بريرى وهو هارب من مواجهة الواقع وفى أقسى حالاته الانهزامية،

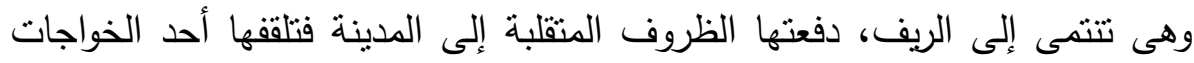

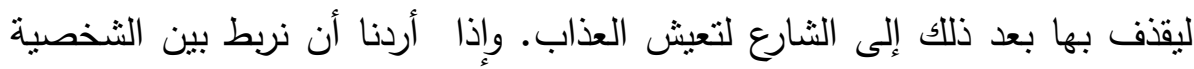
وبنيتها الدالة فسنجد فى مسيرة ريرى وجهًا من وجوه المصبر المصرى الذى انفصل

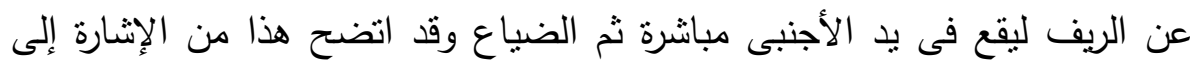
الخواجة العجوز الذى استخدمها خادمة وخليلة "(ج9) .

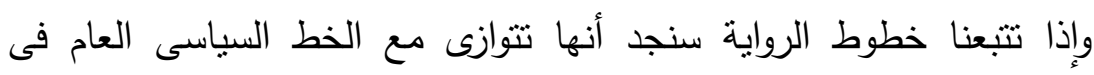
مصر" فكما أن الثورة، هى ثورة على السابق، فإنها وليدة لهذا السابق فقد حملها

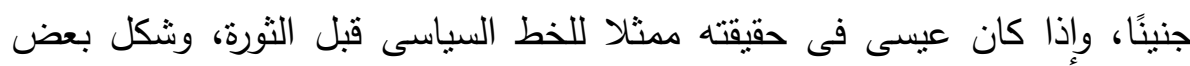




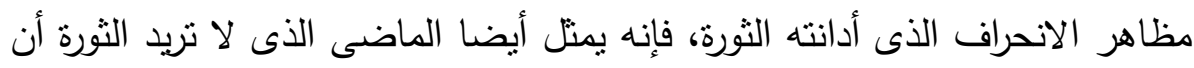

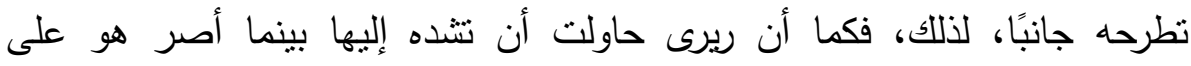

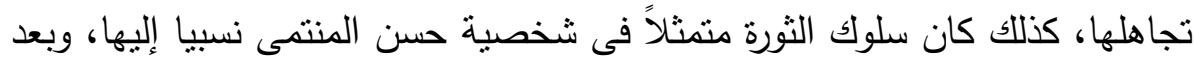

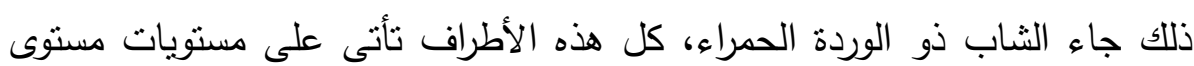
الدلالة فى شخصية ريرى ـ إن الابنة هى الدد الآخر الذى يكمل الدلالات كلها،

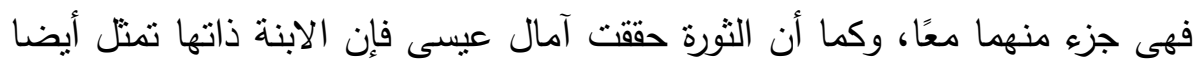
أمل عبسى فى الاستمرار بعد أن عاش فى حياة العقم مع قدرية"(·").

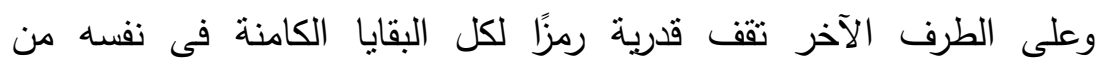

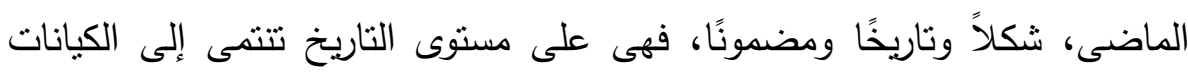

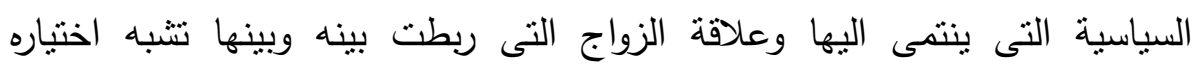

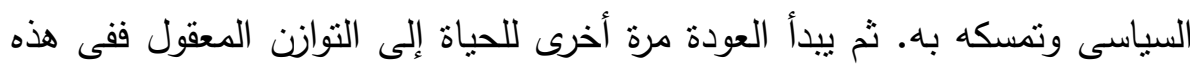
اللحظات الحاسمة يعيد النظر فى حياته ويراجع مواقفه السياسية ومن ثم فهو يرفضها

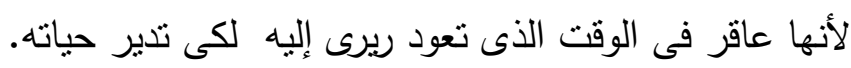

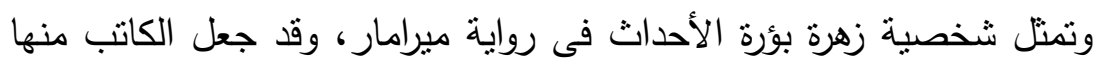

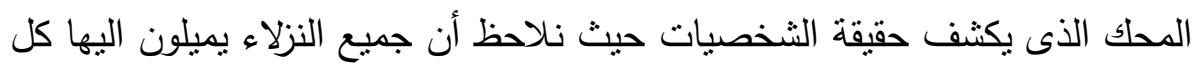
على طريقته "ولكنها تصد طلبة مرزوق وحسنى علام فقد مضى عهد الباشوات،

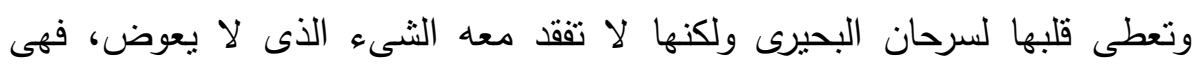

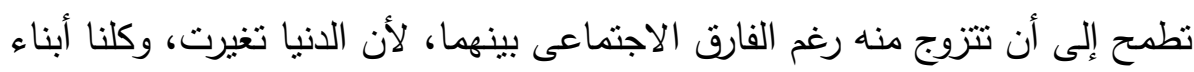

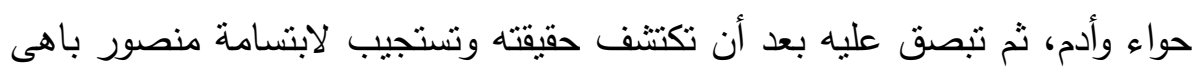
ولكنها لا تعتبر عواطفه إزاءها شيئًا أبعد من المجاملة ثم ترفض بائع الجرائد ميسور

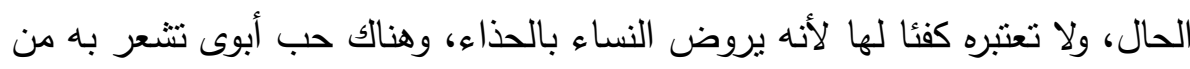

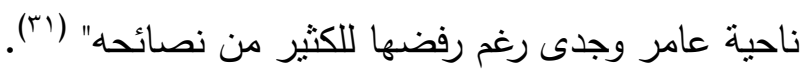

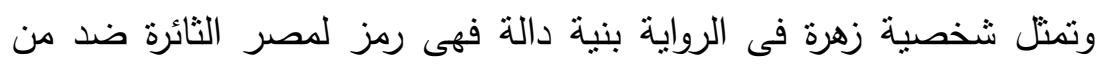
حاولوا استغلالها بعد وفاة أبيها. تماما مثل مصر ، بعد وفئ دفاة سعد زغلول أبو الأمة 
المصرية كما كان يوصف، ثم إنها ثارت ثانيًا ضد من أرادوا الاستفادة من ورائها من

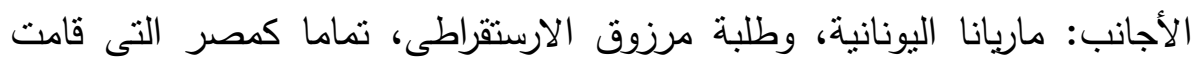

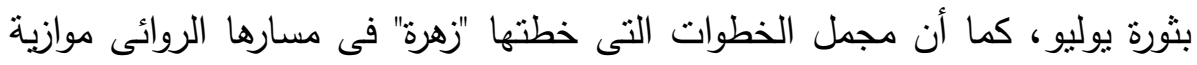

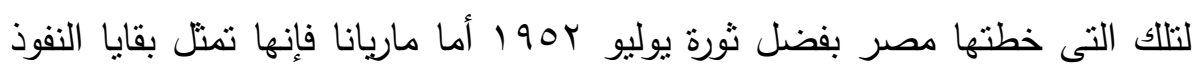
الأجنبى فى مصر الذى لم يعد له أى نأثير فعلى فى مجرى الأحداث، ومن ثم فلم

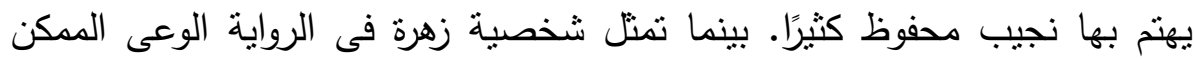

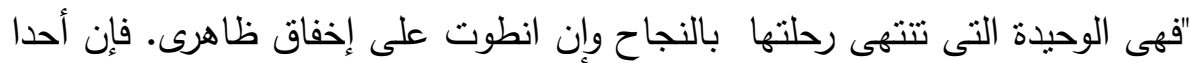

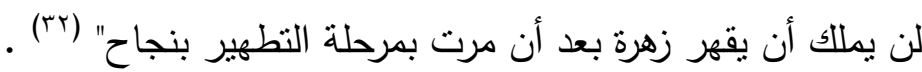

\section{ثالثا: هرحلة اليبرالية الجديدة بعد الثورة}

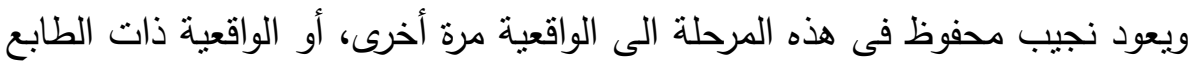

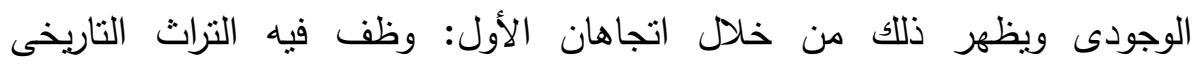

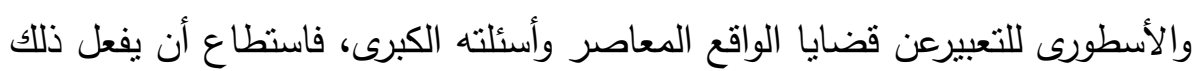

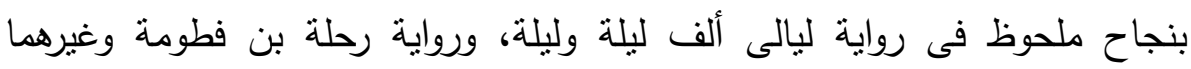

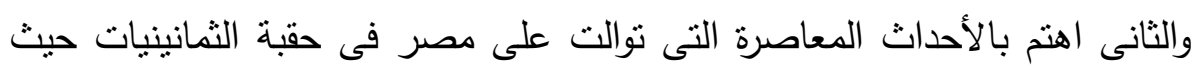
عاد فيها الكاتب إلى عالم الطبقة الوسطى، والحارة.

\section{1- - روية الذات فى علاقتها بالآخر}

يعرض نجيب محفوظ فى رواية أفراح القبة ، شعور عامة الدصريين بعد سياسات

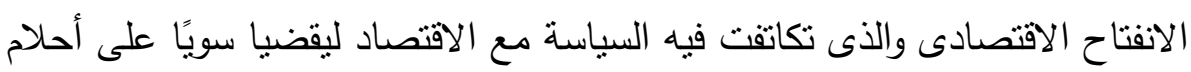

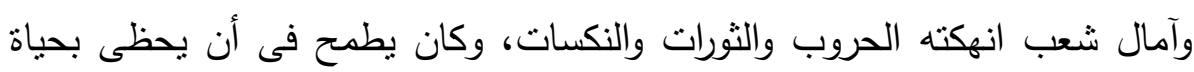

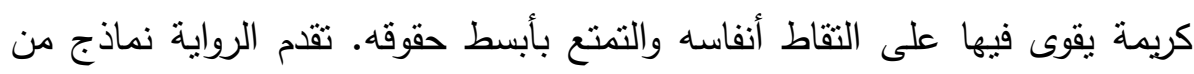
الثخصيات محاصرة بالعفن والسقوط واللامبالاة ترتكب الخطيئة فى إصرار وتعدد، غير أن سياق تدنى الثخصيات يسير فى نواز مع سقوط وتندى المجتمع. 
تعرض الرواية أربع وجهات للنظر لأربع شخصيات هم: طارق رمضان

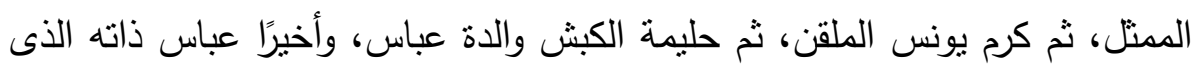

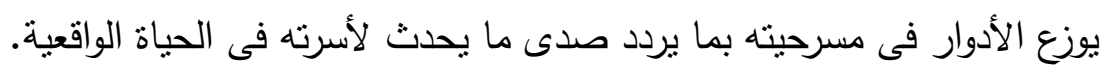

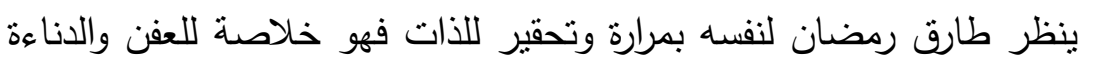

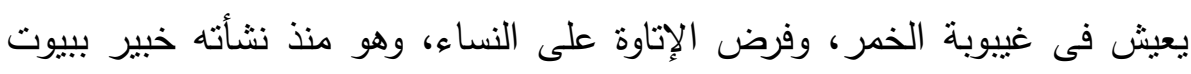

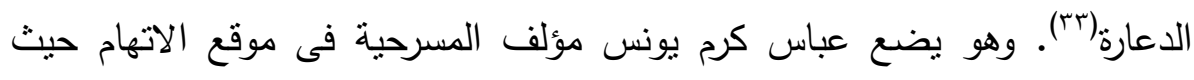

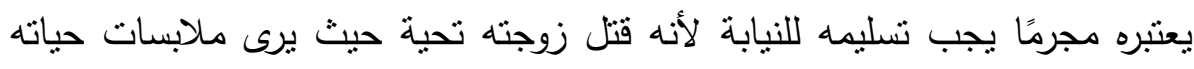

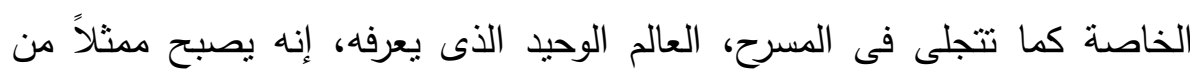

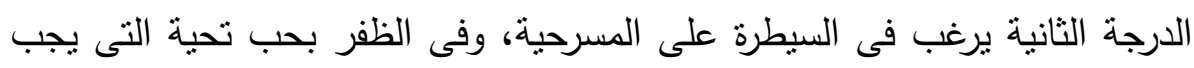

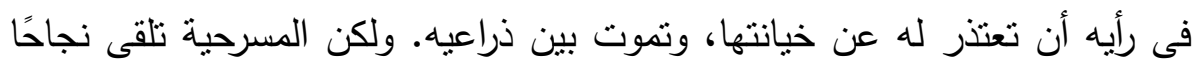

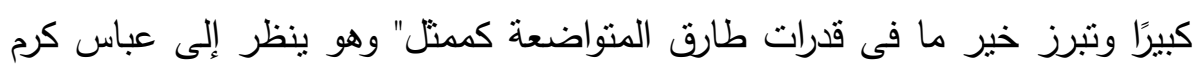

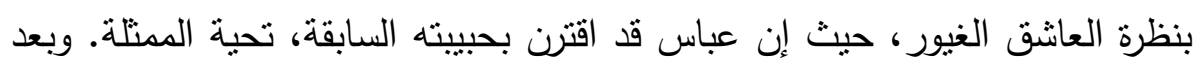

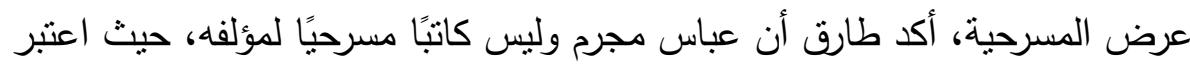

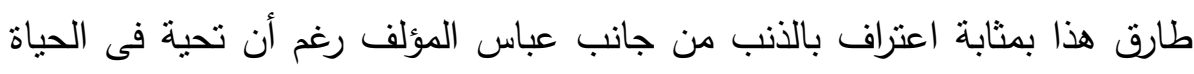

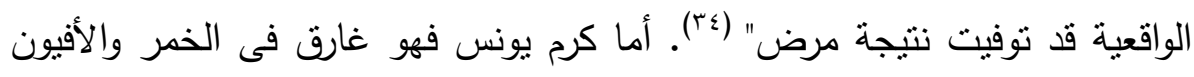

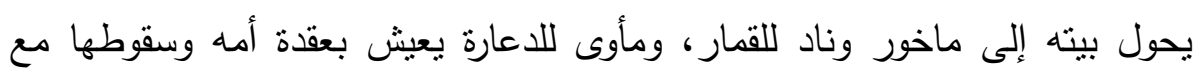

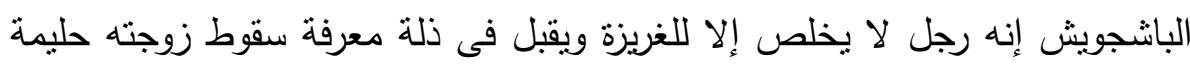
الكبش مع الهلالى ليلة زواجهما وتستفزه نظرات الإدانة والاحتقار من إبنه عبله عباس.

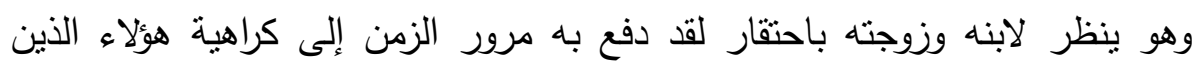

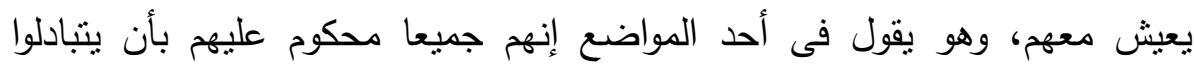

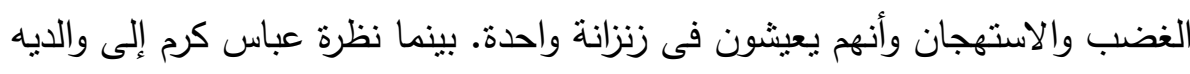
فهى نظرة سلبية فهو برى فيهم صورة القواد والعاهرة.

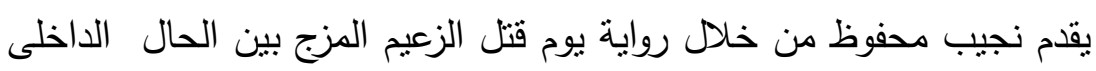

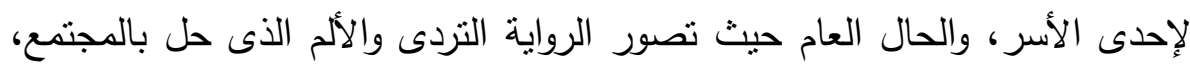


وضيق الخناق على أفراده فى سُبّل المعيشة، بما بحمل فى طياته إدانة لنظام حكم

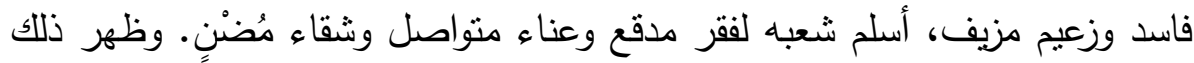
فى قول رندة سليمان مبارك لأبيها: "جاء عصر أكل الناس فيه الكلاب والقطط

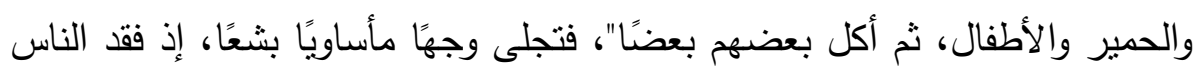
طعامهم فصاروا وحوشا فاقدين آدميتهم"(ro). الرواية تربط بين إطلاق الثعارات على مستوى شخصى، وبين إطلاقها على

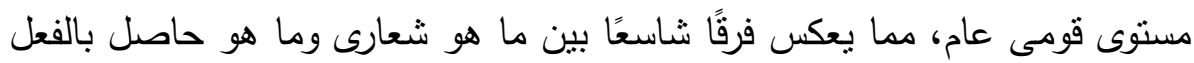

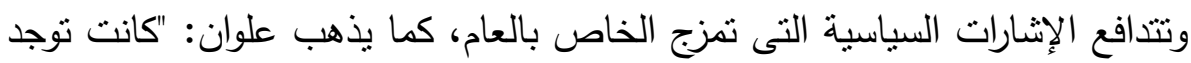
أيام حلوة، كان لأبى وأمى وجود فى البيت، وكان يوجد حوار وضحك وحماس التسان

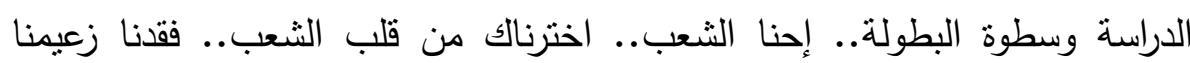

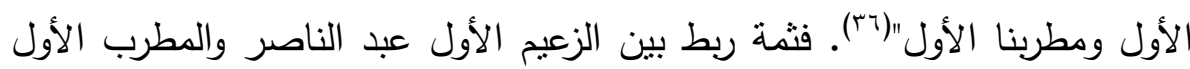

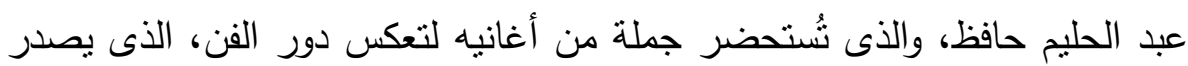

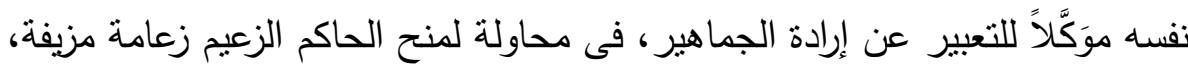
لا تستتد إلى شرعية جماهيرية حقيقية. تبدوالمفارقة صارخة؛ إذ يفشل بطل النصر والسلام- هكذا كما روج الحاكم لنفسه- فى أن ينال رضى شعبه الساخط عليه، بينما ينذكر الثعب سلفه عبد الناصر

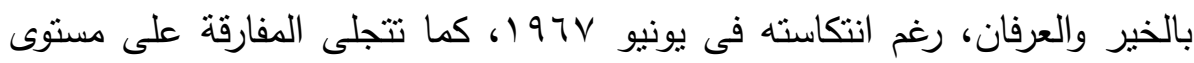

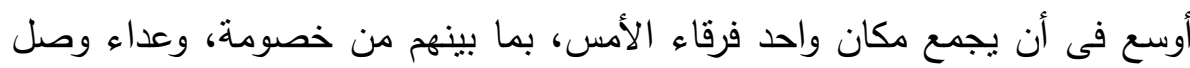
إلى حد الحرب، فإذا بهم يجتمعون فى مكان واحد يضم الثعب الساخط والسياح

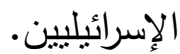

"خرابة صغيرة بمائة ألف...الجرائم الأكاديمية فى الجامعة..كم عدد أصحاب الملايين؟ ... الرشوة عينى عينك وبأعلى صوت ... الاستيلاء على الأراضى ...

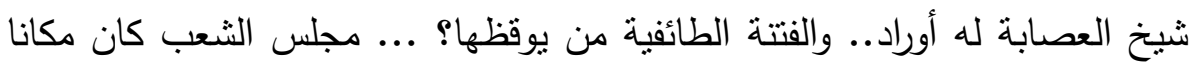
للارقص فأصبح مكانا للغناء .. الاستيراد بدون تحويل عملة.. أنواع الجبن" (FVادئ. 
لتصل الرواية إلى الحكم على الحاكم بالفشل: "ما هو إلا ممثل فاشل". تعرض الرواية لثلاث شخصيات رئيسية الجد والحفيد علوان، وخطيبة الحفيد رندة سليمان حيث نرى الجد لا يندم على مراحل الحياة التى مر بها فقد أعطى لكل مرحلة من مراحل حياته حقها مسترشدًا بالحديث الثريف "اعمل لدنياك كأنك تعيش أبدا واعمل لآخرتك كأنك تموت غدا" وهو يعيش حياته منتظرًا قدوم الموت فى أى ئى

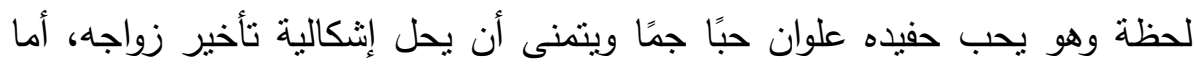
الحفيد علوان فيعتبر جده صديقه الأول ويشعر باليتم بعد أن فقد أبواه أنفسهما فى أنى عمل يتواصل من الصباح حتى المساء وقد خفض محفوظ من مستوى مشاركة الجيل الأوسط فى الرواية، فالأب والأم تكاد تكون نسبة مشاركتيهما معدومة، يمكن أن يعثبر هذا الحذف لدور الجيل بنية دالة فهذا الجيل الذى شهد الدحاولة الاشتراكية التحريرية للعهر الناصرى، ورأى وشارك فى عملية نقد ثلك المرحلة إبان حكم السادات، فكأنه بإلغاء مشروعه الإنتاجى والحضارى استحق بالتالى أن يؤدى ذلك إنى إلى إلغائه وحذفه من خارطة الثخصيات.

ب- ب - بوئة الرجل لعلاقته بالمرأة

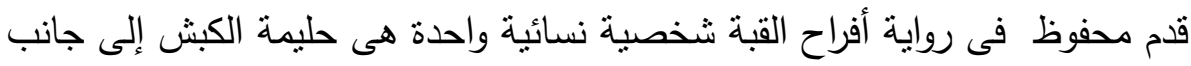
تحية التى نوفيت فى أحداث الرواية "تعيش حليمة الكبش فى فراغ فكرى يؤدى بها إلى الاستسلام لأسلوب حياة مدمرة يفرض عليها أن تتخلى عن كرامتها وأخلاقها

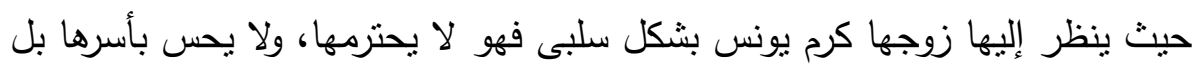
يصرح بقسوة إنها هى التى حاصرته. تصبح حليمة معزولة فى عالم من الإهانات

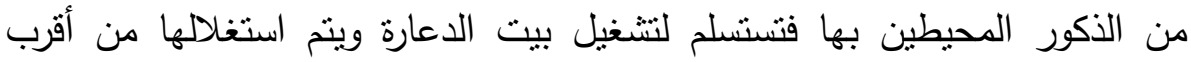

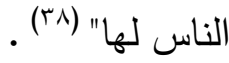


أما عباس فهو يحب تحية ولكنه لا يستطيع أن يوفر لها الراحة الدائمة وهو

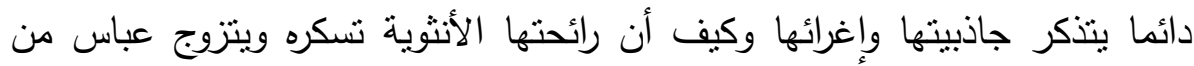
تحية وينجب منها طفلاً وينتهى الأمر بوفاتها هى وطفلهائها.

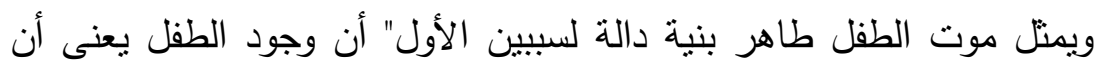

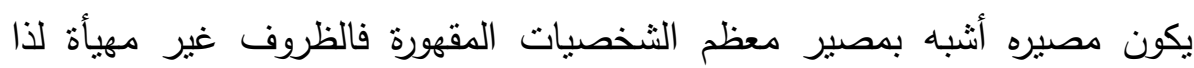
فالأمل غير موجود أو غير محقق والثانى أن موته يؤكد حتمية القدر الذى يؤمن به بهير

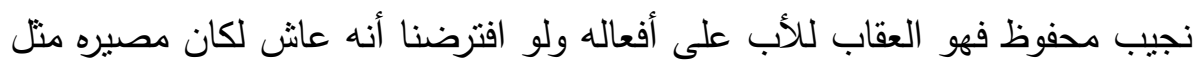

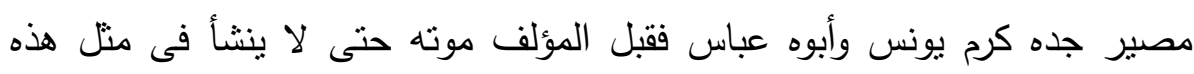

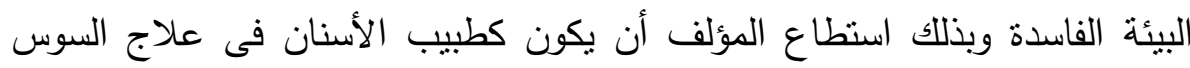

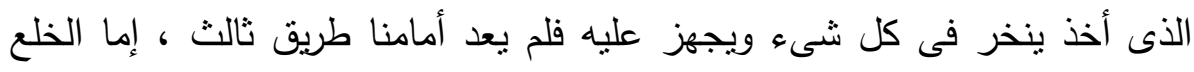

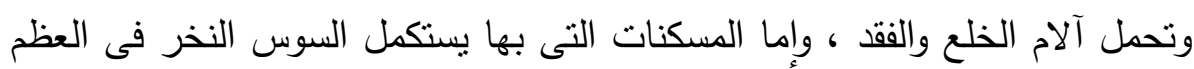
حتى ينهار علينا البناء وهكذا قدم لنا نجيب محفوظ الحالين ولكن بموت الطفل يرغمنا على الخلع والبتر حتى لا يتحمل غيرنا نخر السوس متلما تحملت معظم

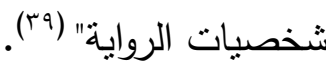

وفى رواية يوم قتل الزعيم يقدم محفوظ علاقة الحب التى تجمع بين علوان

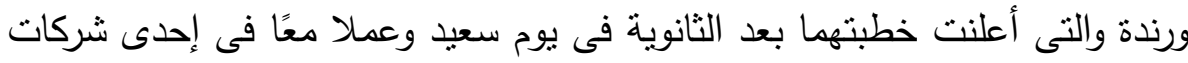
القطاع العام ولكن بعد العمل أضحت الصعاب، الثقة ، الأثاث، أعباء الحياة فئاء

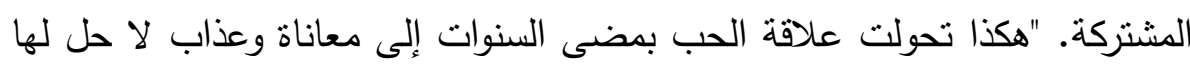

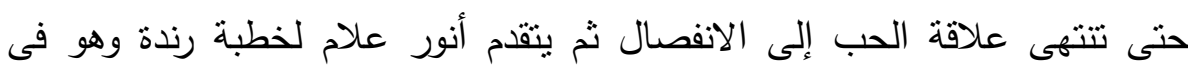

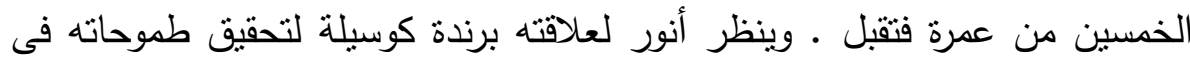

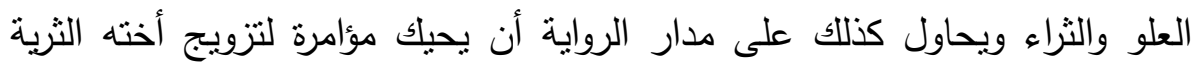

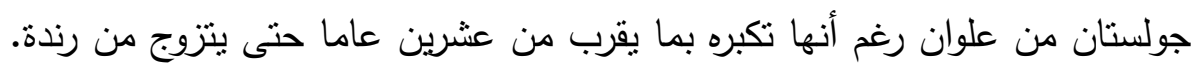

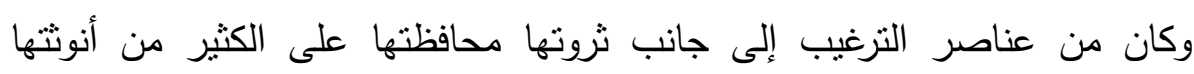


وعندما سأل علوان جده عن رأيه فى زواجه منها. يخبره بأن مزاياه تفوق عيوبه ، لكن

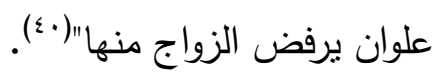

\section{رابعا: رؤية العالم بين الرواية والواقع والأديب}

إذا كان جولدمان يرى أن الكاتب المبدع ينجاوز ذاته الفردية ليعبر عن وعى الطبقة الاجتماعية، فإن ذلك ينطبق على نجيب محفوظ تمامًا فهو ابن طبقته البرجوازية

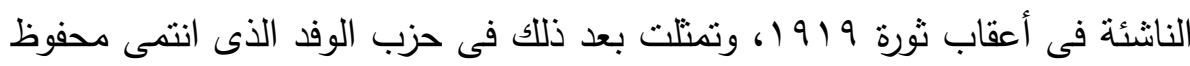

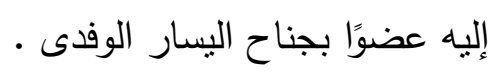

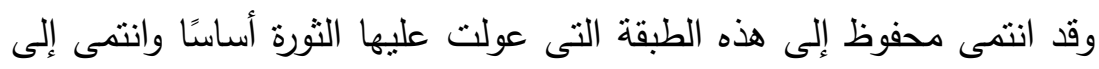

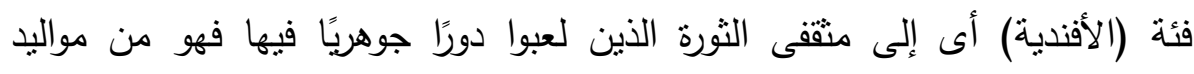

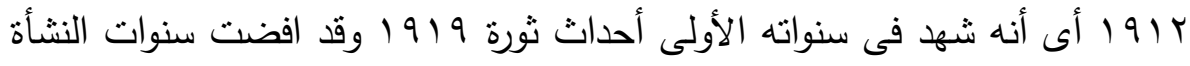

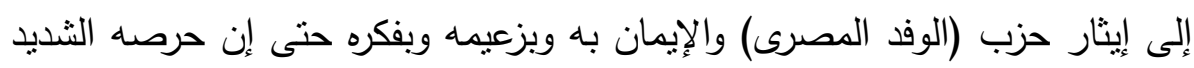

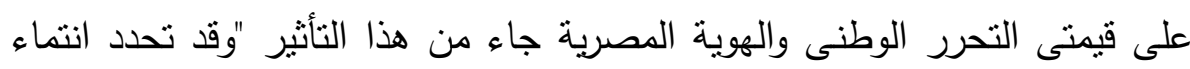

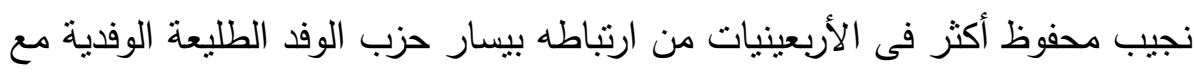

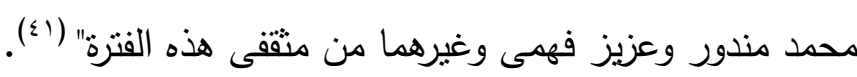

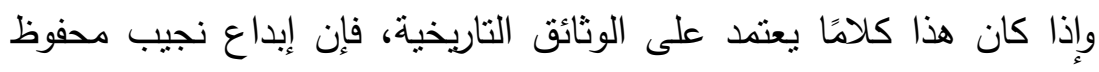

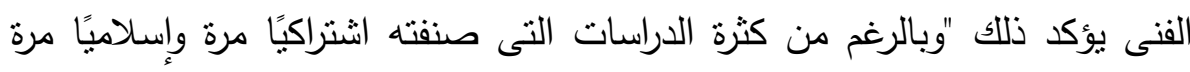

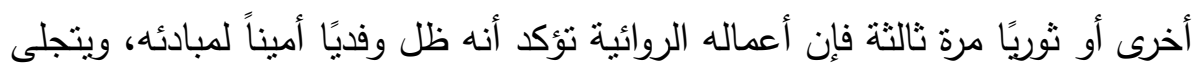

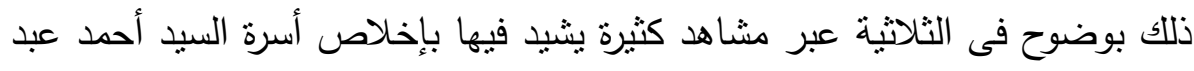

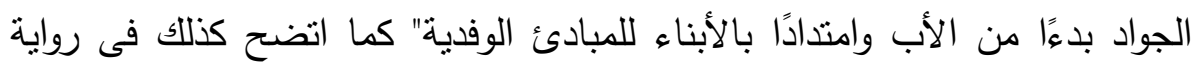

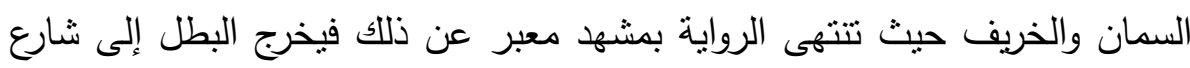

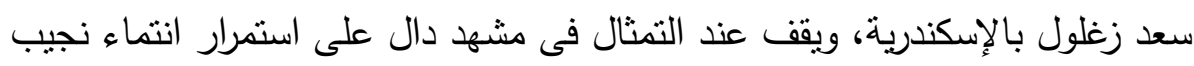

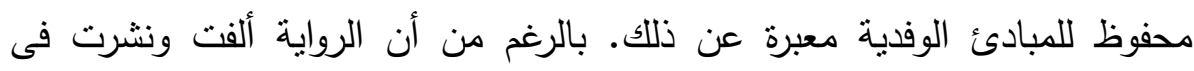

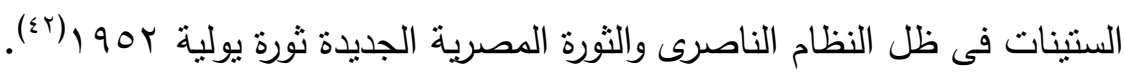


وقد كرس ذلك أيضا فى روايته ميرامار ذلك البنسيون السكندرى الذى تجتمع فيه كل القوى الوطنية ممنلة فى شخصيات سكان البنسيون، والتى تحوم حول زهرة (التى نظن أنها رمز مصر فى نلأك الفترة التى انتصرت للفيلاحين وللطبقة الجديدة)

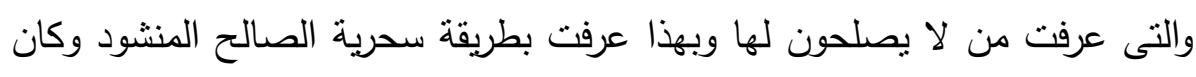

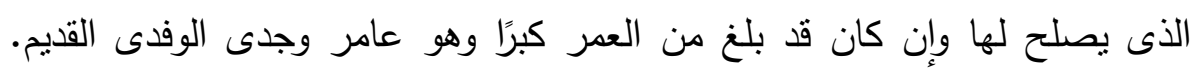

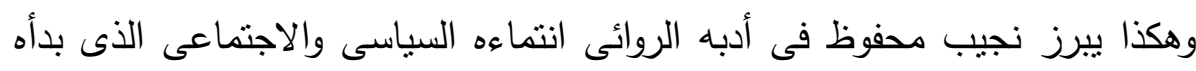

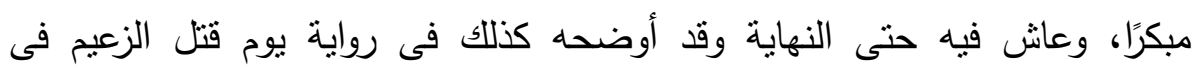

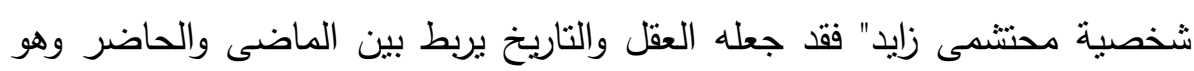

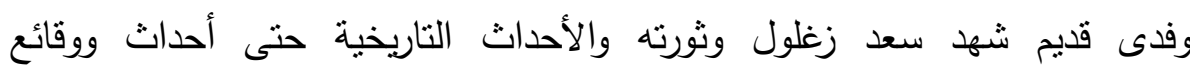

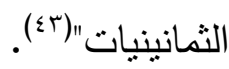

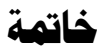

يمكننا أن نحدد بعض النتائج والاستخلاصات فى هذه الدراسة بعد الممارسة النظرية

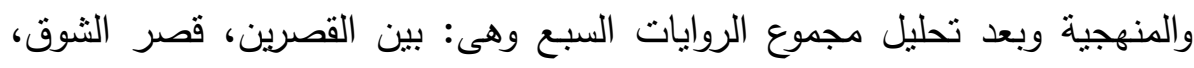

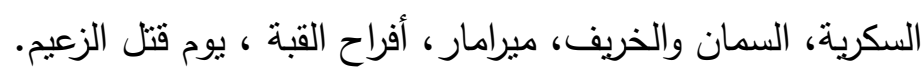

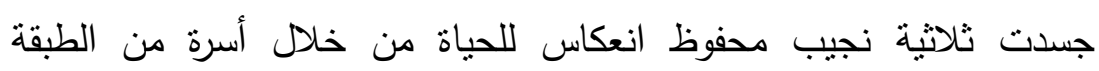

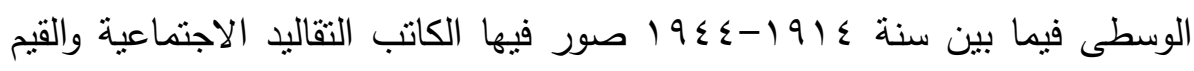

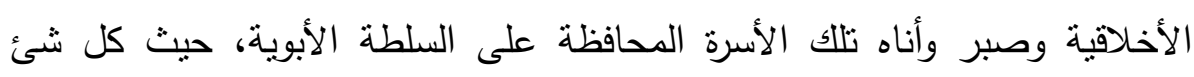

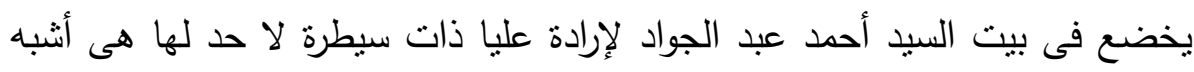
بالسيطرة الدينية، حتى الحب نفسه يخضع لهذه السيطرة وفى تقديمنا لحياة هذه الأسرة

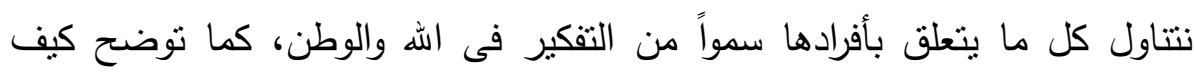


تحرر الأبناء من سيطرة السلطة الأبوية بالتنريج، وتربط ذلك بالسياسة العامة للوطن

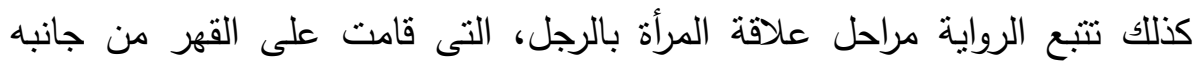
والاستكانة من جانبها. مثلت رواية السمان والخريف وثيقة هامة للعلاقة المعقدة بين الثورة ، وبين جيل كامل عزلتهم الثورة بضربها للأحزاب، ووجدوا أنفسهم فى أسر مفارقة غريبة فهم

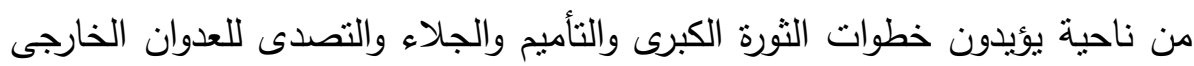

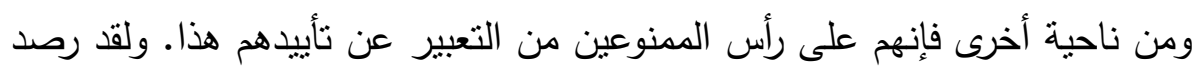

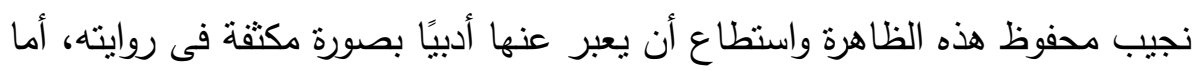
فى رواية ميرامار فقى هذا البنسيون نجد التجسيد الحى لماضى يحكم فيه الاستعمار

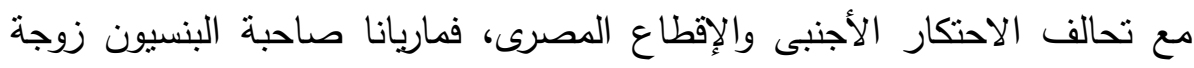

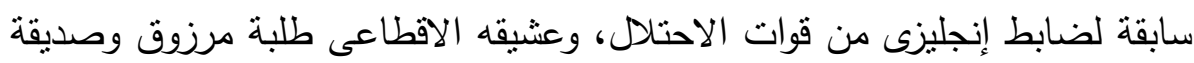

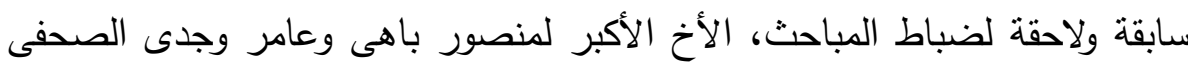

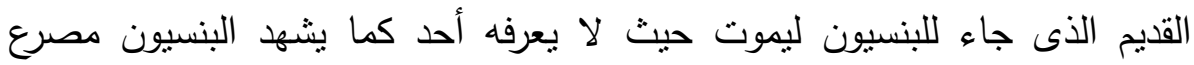

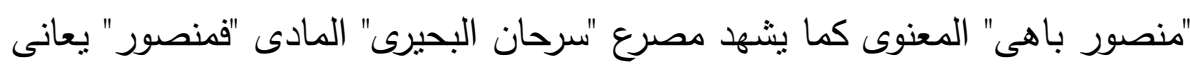

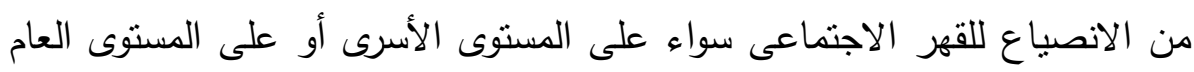

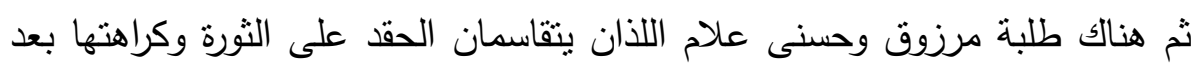

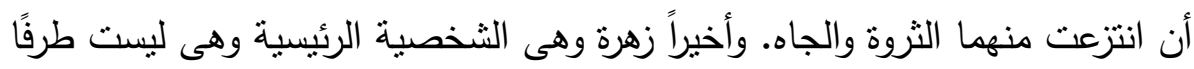

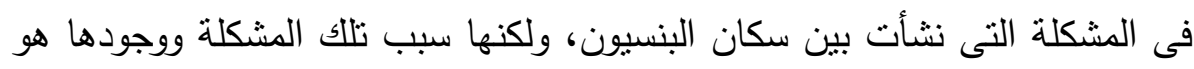

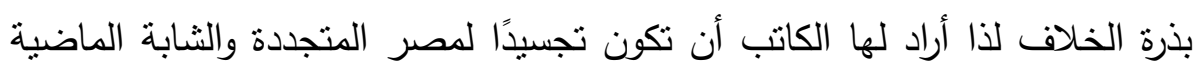

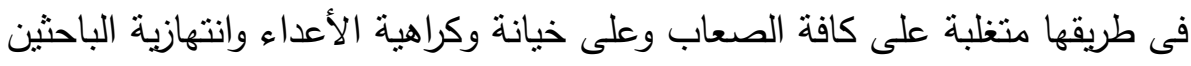
فى الثورة عن منافعهم.

أما رواية "أفراح القبة" فنخصياتها جميعا تعمل فى مجال المسرح، ولها

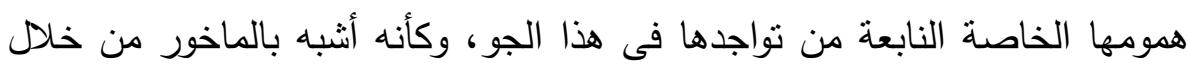


شخصيات متدنية هامشية من قاع المجتمع، وأخرى برجوازية قفزت اجتماعيًا لتستأثز

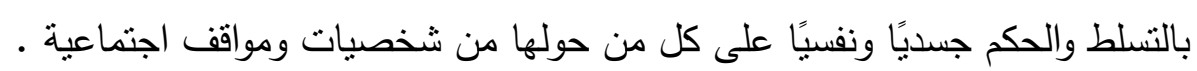
وأخيرا يصحبنا محفوظ إلى مصر الثمانينيات، إلى مصر النصر والهزيمة، إلى مصر الحضارة ومواجهة التحديات من خلال روايته بوم قتل الزعيم "حيث يصدمنا الكاتب بأفكاره الجريئة، وبواقع مصر فى ذللك الوقت الذى تنكاتف فيه السياسة مع الاقتصاد ليقضيا سويًا على أحلام وآمال شعب أنهكته الحروب والثورات والنكسات وكان بطهع أن يحظى بحياة كريمة يقوى فيها على التقاط أنفاسه والتمتع بأبسط حقوقه.

\section{المراجع}

Goldmann, Lucien, The Hidden God, A Study of Tragic Vision in the Pensees - of Pascal and Tragedies of Racine, Rutledge and Kegen Paul, New York, The Humanities' Press,1976, pp 1-3.

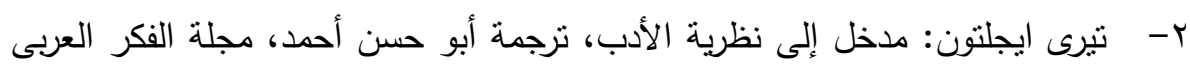

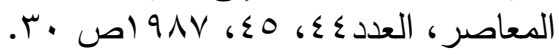

Cohen, Mitchell The wage of Lucien Goldman Tragedy, Dialectics, and A _ Hidden God, Journal of Politics, Vol. 58, Issue, I, p.278,1996.

ع- صالح سليمان، سوسيولوجيا الرواية السياسية، القاهرة، الهيئة المصرية العامة

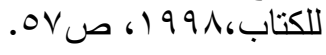

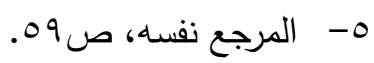




$$
\begin{aligned}
& \text { צ- صلاح فضل، منهج الواقعية فى الإبداع الأدبى، القاهرة، دار المعارف، الطبعة }
\end{aligned}
$$

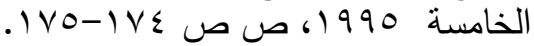

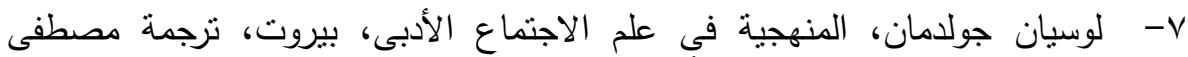

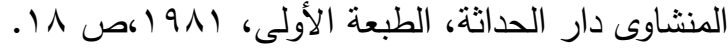

$$
\begin{aligned}
& \text { 1- سليمان الثطى، الرمز والرمزية فى أدب نجيب محفوظ، القاهرة، الهيئة العامة للكتاب، }
\end{aligned}
$$

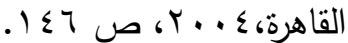

Oersen, Sheridene Barbara The Representation of Women in Four of Naguib - $\quad 9$ Mahfouz's Realist Novels: Palace Walk, Palace of Desire, Sugar Street and Midaq Alley, A mini-thesis submitted in partial fulfillment of the requirements for the degree of Master of Arts in the department of English, the University of the Western Cape, November, 2005, p 34.

$$
\text { انظر الرسالة على موقع etd.uwc.ac.za }
$$

• 1 - نجيب سرور ، رحلة فى ثثلاثية نجيب محفوظ، القاهرة، دار الثروق، V. . . القاهرة،

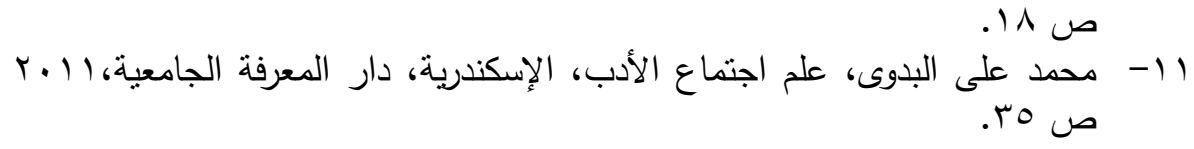

Aftidi, Mehnaz Moma, Nagub Mahfouz and Modern Islamic Identity, Doctor -1 r of Literature and Philosophy in Religious studies at the University of south Africa, 2008, p. 33.

$$
\text { uir.unisa.ac انظر الرسالة على موقع }
$$

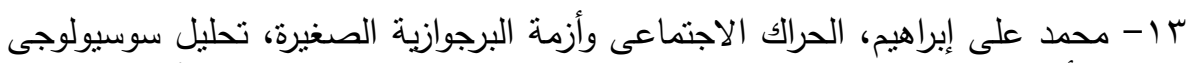

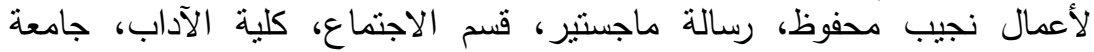

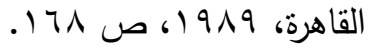

ء ا - طه وادى، صورة المرأة فى الرواية الواقعية، عند نجيب محفوظ، أمير الرواية العربية

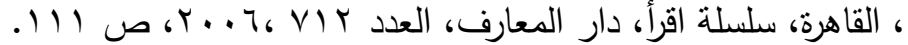

$$
\text { 10 - سليمان الشطى، مرجع سابق، ص 0. ه. }
$$

Aftidi, Mehnaz Moma, op.cit, p. 63.

$$
\begin{aligned}
& \text { IV سليمان الشطى، مرجع سابق، ص107 } \\
& \text { 1 ا- طه وادى، مرجع سابق، ص r II I. }
\end{aligned}
$$

9 ا- عاشور، البحث عن زعبلاوى، القاهرة، الهيئة المصرية العامة للكتاب، ج ـ . ب، ص 
• †- إبراهيم فتحى، العالم الروائى عند نجيب محفوظ، القاهرة، الهيئة المصرية العامة

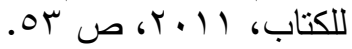

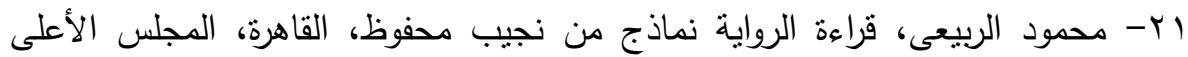

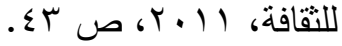

YY- لطيفة الزيات، نجيب محفوظ الصورة والمثال، القاهرة، الهيئة العامة للكتاب، مكتبة

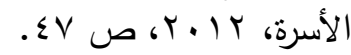

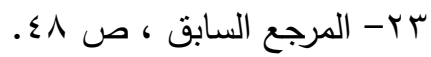

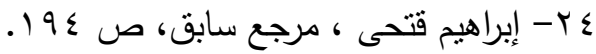

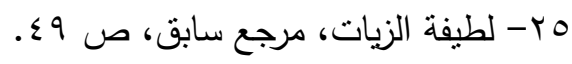

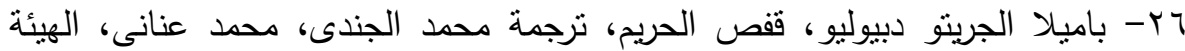

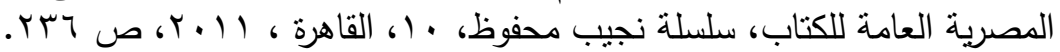

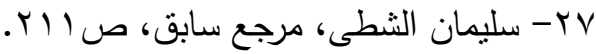

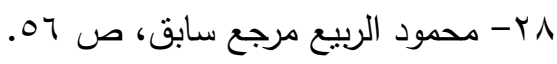

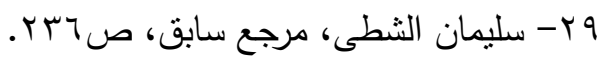

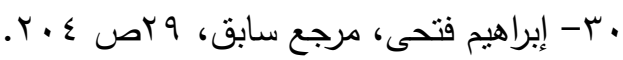

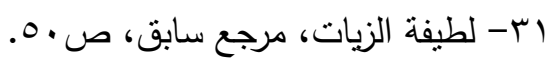

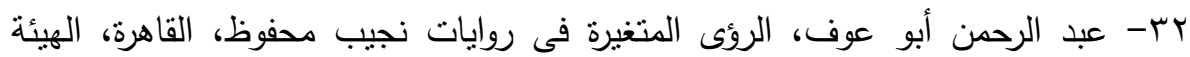

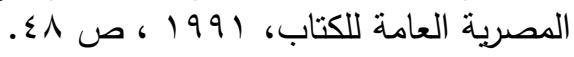

r T- محمد عنانى، ماهر شفيق فريد، نجيب محفوظ فى عيل، عيون العالم، القاهرة، الهيئة

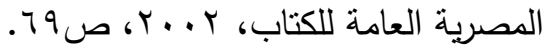

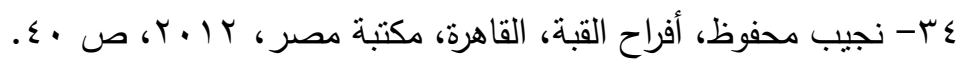

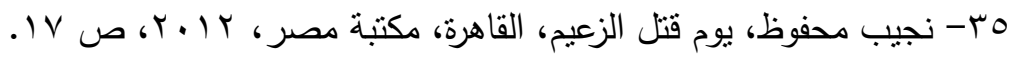

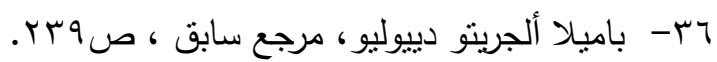

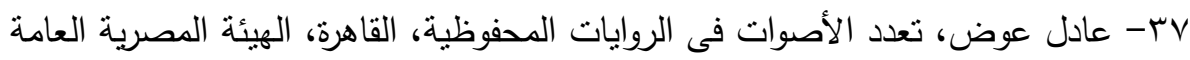

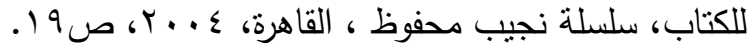

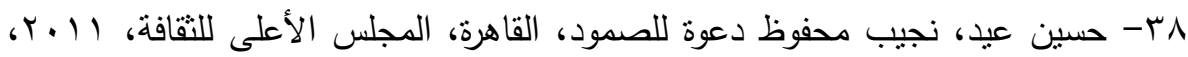

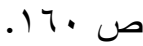

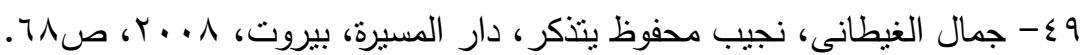




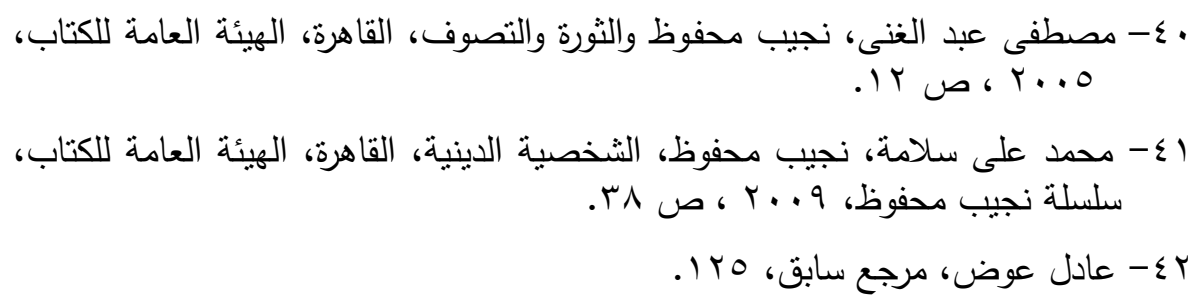

\section{Mona Al Metwally}

This article tries to identify the genetic sturcturalism as an applicable methodology to understand Arabic novel nature, so the study used Naguib Mahfouz work: as a model. According to the analysis of the chosen novels, they represented total structure that clarifies the author's view of the world. The chosen novels included: Bain Elkassrain, Kasser El-Shouk, Al-Sokaria, Al-Saman wel Khareef, Miramar, Afrah Al-quba and youm qatl El-Zaim. 